\title{
Caracterización de MYPES en el municipio de San Vicente
}

\author{
Luis Alfredo Chacón Monterrosa ${ }^{1}$ \\ Recibido en 25 de enero de 2017, aceptado el 22 de junio de 2017
}

\begin{abstract}
Resumen
La presente investigación consolida una serie de concepciones teóricas, desde los inicios y toma de importancia de las MYPES a nivel Internacional, hasta la definición de Latinoamérica y en específico para El Salvador. Las diferentes teorías y autores a lo largo del tiempo han ido cambiando hasta convertir al sector MYPES, como parte importante del desarrollo en los diferentes países y como potenciador de las industrias, dado que la experiencia ha demostrado que las grandes empresas inician como tal y se desarrollan con el tiempo, con las condiciones y el empuje de emprendedores visionarios.
\end{abstract}

\section{Palabras clave}

MYPES, Municipio de San Vicente, desarrollo, Micro y pequeña empresa, microempresa, empresa, empleo.

\section{Abstract}

This research consolidates a series of theoretical conceptions, from the beginning and importance of the MYPES at the international level, to the definition of Latin America and specifically to El Salvador. The different theories and authors over time have been changing until the MYPES sector, an important part of development in different countries and as an enhancer of industries, since experience has shown that large companies start as such and Develop over time, with the conditions and drive of visionary entrepreneurs.

\section{Keywords}

MYPES, Municipality of San Vicente, development, Micro and small enterprise, microenterprise, enterprise, employment.

1. Maestro en Finanzas por la Universidad Centroamericana José Simeón Cañas. Ichac182@hotmail. com 
56 Caracterización de MYPES en el municipio de San Vicente.

Luis Alfredo Chacón Monterrosa

\section{Introducción}

Los empresarios MYPES en El Salvador se encuentran con una serie de obstáculos y dificultades que les llevan al sector a adquirir características como baja productividad, informalidad en cuanto a cumplimiento de obligaciones de ley, baja remuneración a los factores productivos y en especial a la mano de obra. Cuestión por la que debemos como investigadores y ciudadanos debemos preocuparnos por encontrar verdaderas propuestas que ayuden a su desarrollo sostenible.

Es por ello que en la presente investigación se realiza una encuesta de opinión a 25 microempresarios ubicados en la ciudad de San Vicente, con el fin de comprender de primera mano los obstáculos y la percepción de los mismos, usando herramientas estadísticas en SPSS para lograr un análisis de los datos que nos lleve a entender de la mejor forma el panorama.

\section{Planteamiento del problema}

Existe dentro de las condiciones del municipio de San Vicente una serie de problemas - muchos de corte social - atribuidos a la población local en específico. Para generar impactos considerables y medibles en más corto plazo, además sin mayor dependencia iniciativas de ley y recursos cuantiosos provenientes del erario público, es necesario buscar alternativas desde una óptica más descentralizada en concreto desde la óptica de las MYPES, se presentan una gama de opciones prometedoras que pueden impulsarse desde el asocio municipal y privado.

\section{Objetivo General de la Investigación}

La investigación se desarrolla para poder entender las características y principales obstáculos de las MYPES en el municipio de San Vicente, a modo que se pueda hacer un diagnóstico, usando la investigación de campo como herramienta principal. Fundamentando las bases para posteriores estudios que ofrezcan alternativas, para el desarrollo sostenible en el municipio a través de iniciativas impulsadas desde diferentes frentes.

\section{Fundamentos Teóricos}

\subsection{Definición de MYPES}

Existen una serie de definiciones para las MYPES, que varían entre país y autor, lo que denota la complejidad del tema. Es importante denotar que el término, es acrónimo de Micro y pequeña empresa y que se componen de categorías individuales. Zevallos (2003) afirma que en los diferentes países, se usan varios criterios para poder clasificar a las empresas: empleados, ventas, activos y otros. Los criterios difieren dependiendo del país, aunque con frecuencia los expresa- 
dos anteriormente tienen mayor peso, hablando del contexto latinoamericano. En la tabla II, se muestra la clasificación en diferentes países de las categorías microempresa, mediana empresa y gran empresa, tomando en cuenta los criterios de organismos técnicos de cada uno de los países listados, donde se denota la predominancia del criterio de número de empleados, en la mayor cantidad de países, aunque aún en esta categoría no existe convergencia en todos.

Tabla 1. Definiciones de empresas por país

\begin{tabular}{|c|c|c|c|c|c|}
\hline & Criterios & Microempresas & Pequeña empresa & Mediana empresa & Gran empresa \\
\hline Argentina $^{a}$ & Ventas & Hasta 0.5 & Hasta 3 & Hasta 24 & Más de 24 \\
\hline Boliviab $^{\mathrm{b}}$ & Empleos & Hasta 10 & Hasta 19 & Hasta 49 & Más de 49 \\
\hline Chile $^{c}$ & Ventas & Hasta 2400 & Hasta 25000 & Hasta 10000 & Más de 100000 \\
\hline Colombia $^{d}$ & Empleos & Hasta 10 & Hasta 50 & Hasta 200 & Más de 200 \\
\hline Costa Rica & Empleos & Hasta 10 & Hasta 30 & Hasta 100 & Más de 100 \\
\hline El Salvador ${ }^{f}$ & Empleos & Hasta 4 & Hasta 49 & Hasta 99 & Más de 99 \\
\hline Guatemalas & Empleos & Hasta 10 & Hasta 25 & Hasta 60 & Más de 60 \\
\hline México $^{\text {h }}$ & Empleos & Hasta 30 & Hasta 100 & Hasta 500 & Más de 500 \\
\hline Panamá & Ingresos & Hasta 150000 & Hasta un millón & Hasta 2.5 millones & Más de 2.5 millones \\
\hline Venezuela & Empleos & Hasta 10 & Hasta 50 & Hasta 100 & Más de 100 \\
\hline
\end{tabular}

Fuente: Tomado de Zevallos (2003)

OIT (2010) confirma las definiciones, delimitándolas de forma general por número de empresa con microempresa por 1-10 trabajadores, pequeña empresa por 10-100 trabajadores y mediana empresa por 100-250 trabajadores. Esto sin importar el tipo de empresa y con independencia de su personalidad jurídica.

En referencia a la Unión Europea microempresa se denomina a toda empresa con menos de 10 trabajadores, así como con un nivel de ventas anuales menor a dos millones de euros. En Estados Unidos la entidad a la entidad Micro Enterprice Works (Asociación para el fomento de las Microempresas), define microempresa con menos de 5 trabajadores (Tobar, 2014).

Es claro el avance y enriquecimiento conceptual en torno a las MYPES a lo largo del tiempo a nivel internacional, hasta ser consideradas como legitimas generadoras de desarrollo, logrando conseguir el apoyo de organismos multilaterales para la diseminación de sus actividades.

Las MYPES han presentado una evolución conceptual a lo largo del tiempo que se resume a continuación (Alvarez, 2009) 
58 Caracterización de MYPES en el municipio de San Vicente.

Luis Alfredo Chacón Monterrosa

Tabla 2. Evolución conceptual de MYPES

Periodo

Teoría

\begin{tabular}{cl}
\hline Las MYPES resaltaban por su mano de obra, adaptabilidad y utilización de \\
factores productivos locales, los cuales eran una de las cuantas características \\
que se le atribuían. Pensando en que dichas empresas, llegarían a conformar \\
las grandes empresas en el futuro \\
Surgieron dos visiones contrapuestas sobre las MYPES, una sobre la que las \\
asociaba con el subdesarrollo bajo la postura tradicional de la industrial- \\
ización y otra que las consideraba como claves para el desarrollo industrial sin \\
los males del fordismo \\
Se presenta también evidencia respecto a que países con estructuras más \\
flexibles e informalidad, mostraban una tendencia recesiva menor, debido a \\
su potencial para absorber a la población desechada por el sector formal \\
El Banco Mundial, ayuda a las PYME argumentando que favorecen la \\
competencia y el emprendimiento, adicional que las PYMES son más \\
productivas que las grandes empresas, aunque sin el apoyo del sector \\
financiero.
\end{tabular}

Fuente: Elaboración propia en base a Alvarez (2009)

\subsection{Importancia de las MYPES}

Tobar (2014) presentan una serie de ejemplos sobre la participación de las MYPES en la estructura de empleo y la generación de riqueza. En EE.UU. donde se generan 130 millones de puestos de trabajo que corresponde a 22 millones de negocios (con de los $12 \%$ sobreviviendo a más de 5 años). En la Unión Europea en 2003 representaban el 99\% de las empresas, concentrando más de las dos terceras partes del empleo. En Japón posterior a Segunda Guerra Mundial, cumplen un rol muy importante en la generación de empleo, tomando 2002 como referencia $99 \%$ de las empresas con un 70\% de la ocupación total, traducido a 68 millones de personas laborando en 9 millones de negocios.

El común denominador alrededor del mundo y en mayor grado en los países desarrollados las MYPES tiene un papel muy importante como dinamizantes de las economías, cuestión que es reconocida por sus respectivos gobiernos, que se encargan la función de fortalecer el clima de negocios y brindar apoyo de diferentes formas tanto técnicas como financieras.

Para el contexto Latinoamericano Pérez (2004) citando a Michael, Nebelung (2002) expresa que existen 50 millones de microempresas emplean alrededor de 120 millones de personas. En América Central la pequeña empresa, representa el $20 \%$ del empleo total no agrícola y $8 \%$ del empleo nacional; los micro negocios (microempresa y autoempleo) emplean aproximadamente 4.5 millones de personas. 
En Alvarez (2009) se compila una serie de autores respecto a la Organización Internacional del Trabajo e información de la Unión Europea, haciendo una aproximación practica para comparar las estructuras globales de empleo, de dos regiones con características diferentes, donde se muestra que en los países de Centroamérica, la mayor parte de empleados se encuentran en la microempresa con un $60 \%$ de participación, cuando en la Unión Europea el porcentaje más alto se ubica en la mediana y gran empresa ( sin restarle merito a que el $50 \%$ restante del empleo se ubica entre la pequeña y microempresa.

\section{Gráfico 1. Empleados por tipo de empresa}

a) Centroamérica y Rep. Dominicana

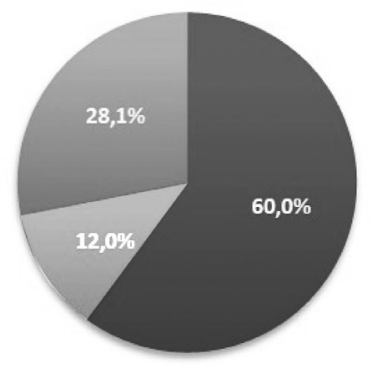

b) Unión Europea

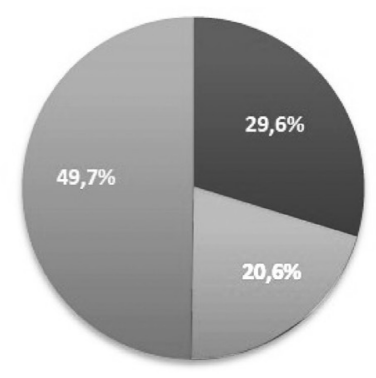

Fuente: Tomado de ALVAREZ (2009)

Respecto a El Salvador las MYPES generan aproximadamente 700 mil empleos directos y aportan 35\% del PIB deacuerdo a información presenta en sitio web CONAMYPE (Consejo Nacional de la Micro y Pequeña Empresa).

\subsection{Clasificaciones de las MYPES}

Las MYPES presentan características bastante heterogéneas, por lo que se vuelve necesario desagregar según una serie de clasificaciones, usando una serie de variables que permiten analizarlas de formas diferentes. Es por ello que, Alvarez (2009) ofrece una clasificación ampliada de MIPYME (Diagrama 1), donde se resumen las clasificaciones consideradas con mayor relevación para el análisis: 
60 Caracterización de MYPES en el municipio de San Vicente.

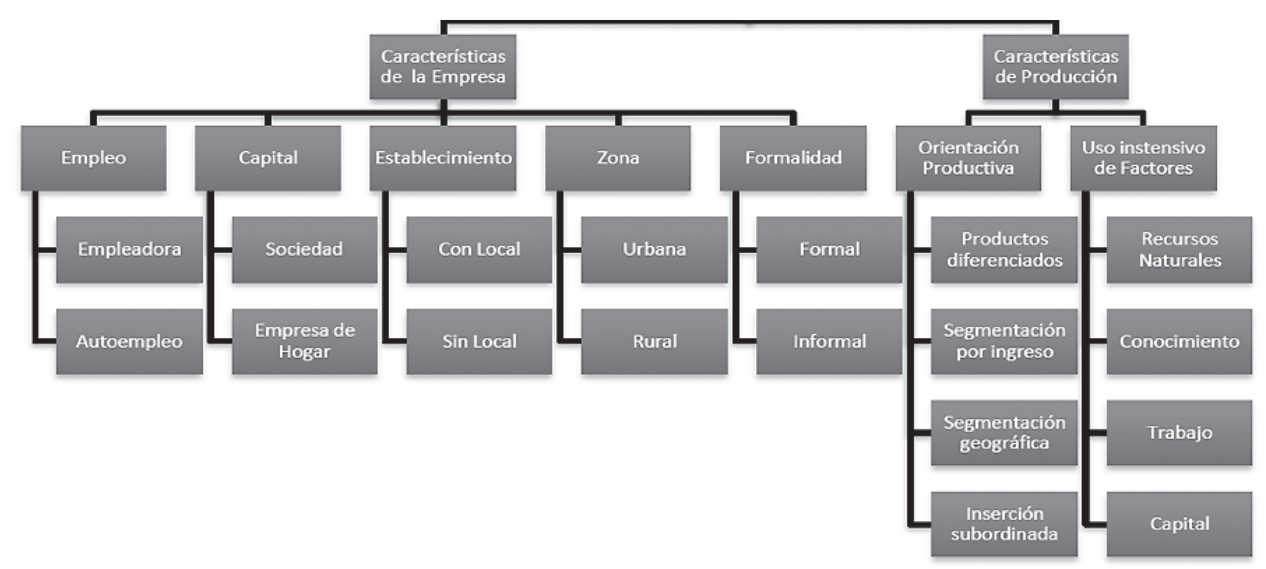

Fuente: Tomado de ALVAREZ (2009)

Dentro de las microempresas principalmente respecto a su tamaño, los mismos dueños pueden volverse empleados y conseguir sus medios de vida a través de su propio trabajo. Por otro lado, empresas empleadoras, son aquellas que contratan mano de obra en diversas posiciones, para poder llevar a cabo las actividades de la empresa.

Las empresas pueden haberse constituido desde su génesis, a través de socios capitalistas donde no existe vínculo familiar. Adicional existen empresas que emplean al núcleo familiar en una serie de actividades de la empresa, ya sea en funciones operativas como en funciones administrativas.

A las MYPES se les asocia el carácter de informalidad, relacionado a no cumplir con los requisitos de Ley, traducidos en el pago de impuesto, registros de empresa, pagos de beneficios a empleados y demás obligaciones que varían según el país en análisis. Aunque existen empresas que principalmente se encuentran encadenadas a actividades productivas y comerciales de la gran empresa que se preocupan por cumplir con los requisitos de ley.

Dependiendo de las características del sector en el que compiten, las MYPES estructuran su estrategia de penetración del mercado, comercializando productos con características diferenciadas, orientadas a un segmento específico de la población (mercado meta) y muchas veces subordinadas a las grandes empresas por la demanda de los bienes y servicios. Con lo anterior se trató de resumir, la serie de factores que intervienen en la clasificación según características de producción. Adicionalmente, en cuento al uso de factores productivos y formas de producir se fundamenta la clasificación "Uso intensivo de factores". 


\subsection{Caracterización de las MYPES en El Salvador}

Una vez definidas una serie de características generalizadas que pueden estar presentes en las MYPES a nivel Internacional, se desciende hacia El Salvador, donde el sector presenta una serie de características delimitadas en Martínez y Beltrán (2002), que los autores desarrollan a partir resultados obtenidos en encuesta de FUNDAPYME, dirigida a pequeñas y medianas empresas:

a) La mayoría de las PYMES son empresas maduras: El 55\% de las empresas pequeñas y medianas tienen más de diez años de haber iniciado operaciones. Al contrario de las microempresas que no presentan mayor estabilidad.

b) El ingreso promedio generado por las PYMES varía en términos geográficos y sectoriales: existe una alta concentración en Área Metropolitana de San Salvador y con mayor nivel de empleados en la industria, seguido por el comercio.

c) Las PYMES tienen como principal cliente al consumidor final: el 54\% de las empresas venden sus productos al consumidor final.

d) Las PYMES Salvadoreñas tienen una oferta exportable poco desarrollada: Únicamente el $14 \%$ de las empresas encuestadas exportan sus productos.

e) Las PYMES tienen poca dependencia de sus proveedores.

f) Los empresarios de las PYMES tienen alto nivel de escolaridad: $28 \%$ de los propietarios y gerentes propietarios tienen título universitario.

g) La mayoría de los empresarios PYME son de género masculino: Únicamente el $26.7 \%$ de los empresarios son mujeres.

h) Las empresas PYME utilizan servicios de internet: $44 \%$ de las empresas encuestadas tienen acceso a internet.

En contraste con los resultados de la encuesta, respecto a la caracterización de la pequeña y mediana empresa en El Salvador, la microempresa presenta un alto nivel de vulnerabilidad debido a una serie de características sintetizadas a partir de Alfaro (2004):

a) Aproximadamente el $72 \%$ se ubican en la zona urbana.

b) Principal motivación de empresario es la subsistencia o mejorar el bienestar del grupo familiar.

c) Casi la mitad de las microempresas se dedican a comercio al por mayor o por menor.

d) Operan bajo un nivel bajo de productividad

e) Nivel de calificación del trabajador el bajo

f) Escaso nivel de complejidad tecnológica

g) El desarrollo de relaciones salariales es muy bajo: Se utiliza trabajo familiar no remunerado

h) Incapacidad de garantías para acceder al sistema crediticio formal 
62 Caracterización de MYPES en el municipio de San Vicente.

Luis Alfredo Chacón Monterrosa

\subsection{Limitaciones de las MYPES}

Dadas las características antes expresadas, el desarrollo de las MYPES se ve frenado por una serie de obstáculos y/o limitaciones que generan inestabilidad en torno a la continuidad y crecimiento de las empresas. Para lo cual OIT (2015), lista las principales limitaciones para que las empresas crezcan y creen mayor empleo; lo hace usando datos de Encuestas de empresas del Banco Mundial donde se le pregunta a propietarios y gerentes sobre sus principales percepciones de las limitaciones.

Gráfico 2. Dificultades que enfrentan las PYMES en los diferentes países - En porcentaje

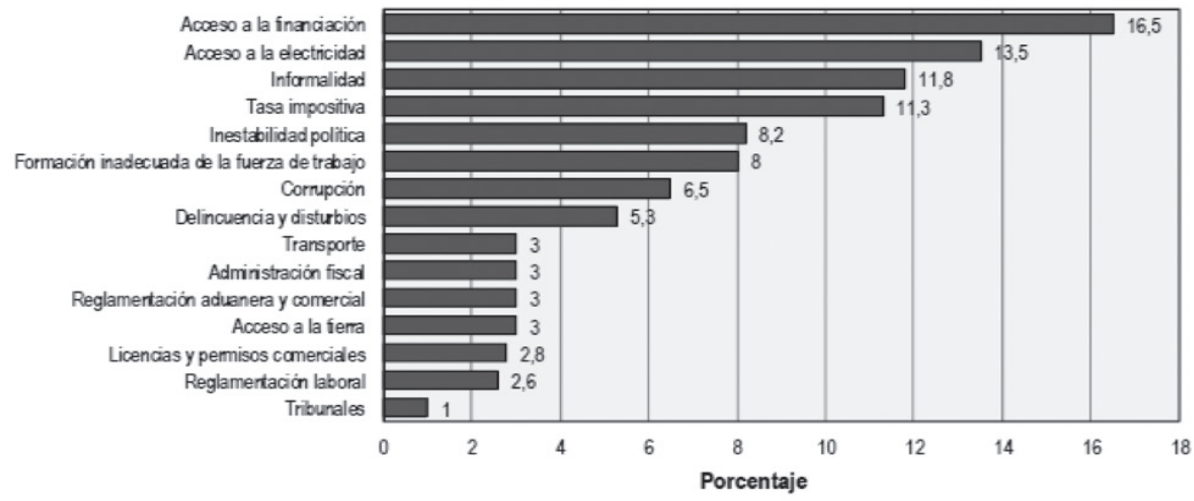

Fuente: Tomado de OIT (2015)

El acceso a la financiación, es un problema que tienen que sobrellevar los empresarios MYPES alrededor del mundo y a menor tamaño de la empresa, la lógica nos dicta que más limitado será el acceso, puesto que los sectores financieros basan su análisis en garantías y predictibilidad de flujos para el repago de la deuda.

En segundo lugar se ubica el acceso a la electricidad que podría tener mayor impacto en empresas con ámbito rural, dado el extensivo acceso a los servicios básicos en los centros urbanos.

La informalidad y la tasa impositiva están relacionadas, dado que las empresas para obtener ahorro respecto a impuestos y demás obligaciones de ley que pueden afectar sus bajos márgenes de ganancia, prefieren caer en la informalidad, que a la vez podría ser un obstáculo para la búsqueda de financiamiento.

Respecto al entorno de El Salvador varias de las limitaciones identificadas por OIT (2015) que las encontramos nuevamente en el estudio de Martínez y Beltrán 
(2002) donde usan la técnica de Triangulación de Métodos para combinar los siguientes instrumentos: a) revisión y análisis de contenido de estudios y documentos existentes sobre el tema; b) entrevistas a profundidad con empresas y actores institucionales claves vinculados al desarrollo de la PYME y c) focus group con empresas, funcionarios públicos y privados y expertos en el tema PYME. Se usan para delimitar las limitaciones como a la vez establecer hipótesis de trabajo tratados a lo largo de la investigación:

1. Acceso al financiamiento: Las condiciones de garantías, sistema de valoración de riesgo crediticio, tasas de interés y plazos de otorgamiento de créditos en los que opera el sistema bancario, limitan el acceso al financiamiento.

2. Funcionamiento del Estado: Los trámites administrativos ante la administración pública, imponen sobrecostos a las empresas PYMES, que obstaculizan su desarrollo dentro de la formalidad.

3. Condiciones de competencia interna: Las prácticas comerciales en el mercado salvadoreño, posibilitan la posición dominante que poseen algunos compradores y proveedores, así como competencia desleal de empresas del sector informal.

4. Infraestructura económica: Las condiciones actuales, elevan los costos de operación y con ello limitan el desarrollo de su competitividad.

5. Dificultades para vender al sector público: Los requisitos y procesos administrativos que existen en los procesos de compra del estado, representan obstáculos en la participación de las PYMES en el proceso.

6. Acceso a mercados externos: El sistema de apoyo a la exportación favorece a las empresas de mayor tamaño

7. Servicios de capacitación y de consultoría: Las características de la oferta de servicios de capacitación y consultoría limita las posibilidades de desarrollo de la competitividad del sector PYME.

8. Acceso a la tecnología: El sistema de innovación del país no favorece la incorporación de mejoras tecnológicas en las PYME.

9. Calidad de y disponibilidad de los recursos: No responde a las necesidades de perfiles ocupacionales que demanda el desarrollo competitivo de las PYME, con lo que representa un costo invertir en capacitación adicional.

10. Legislación laboral: Los altos niveles de tributación y sistema de retención de declaración y pago de impuestos representan un obstáculo para el desarrollo de la competitividad.

\section{Metodología de investigación}

\subsection{Características de la población en estudio}

El Salvador cuenta con una extensión territorial de $20,742 \mathrm{Km}^{2}$, la población es de $6,216,142$ habitantes (2011) y el 62\% reside en zonas urbanas. El país está formado por 262 municipios, repartidos en 14 departamentos, entre los cuales destacan: La Libertad, Sonsonate, Cuscatlán y San Salvador, por contar con la 
mayor densidad poblacional. La mayoría de la población salvadoreña es joven, con un $63.7 \%$ de personas menores de 30 años de edad. Las mujeres son el $\mathbf{5 2 . 8 \%}$ de la población (PNUD, 2016).

San Vicente es un departamento de la zona central de país, se compone de 13 municipios (San Vicente, Apastepeque, Guadalupe, San Cayetano Histepeque, San Esteban Catarina, San Ildefonso, San Lorenzo, San Sebastián, Santa Clara, Santo Domingo, Tecoluca, Tepetitan, Verapaz), con una población de 161,645 habitantes (Digestyc, 2009).

Su cabecera departamental "San Vicente" -foco de la actual investigación encuentra ubicado en el escaño número 25 de 262 municipios por cantidad de habitantes con 53,213 y una densidad poblacional de 199 habitantes por $\mathrm{km}^{2}$. $52 \%$ de la población en área rural y $52 \%$ de la población son mujeres. 31,697 personas con 18 o más años de edad representando un 59.57\% de la población del municipio en edad legal para trabajar (Ibid).

La EHPM (Encuesta de Hogares y Propósitos Múltiples) 2015, nos brinda una serie de indicadores interesantes, sobre el departamento de San Vicente que se contrastan con los de San Salvador -por ser el departamento que alberga la mayor parte de la población- y a nivel país conocer (DIGESTYC,2016):

Tabla 3. Estadísticas Socio-Económicas (San Vicente, San Salvador, El Salvador)

\begin{tabular}{llll} 
Indicador & San Vicente & San Salvador & El Salvador \\
\hline Población Económicamente Activa & $43.5 \%$ & $45.8 \%$ & $44.4 \%$ \\
Tasa de Desempleo & $7.5 \%$ & $6.2 \%$ & $7.0 \%$ \\
Tasa de analfabetismo & $12.3 \%$ & $4.8 \%$ & $10.8 \%$ \\
\%Total Económicamente Inactivos & $26.8 \%$ & $27.3 \%$ & $27.1 \%$ \\
Ingreso per capita mensual & 127.58 & 169.12 & 146.9 \\
\% Personas con remesa & $27.6 \%$ & $12.6 \%$ & $19.2 \%$ \\
\% Hogares en extrema Pobreza & $10.3 \%$ & $4.8 \%$ & $8.1 \%$
\end{tabular}

Fuente: Elaboración propia en base a datos de EHPM 2015

La tasa de desempleo y el analfabetismo para San Vicente, se encuentra por debajo del promedio de país, originada principalmente por el porcentaje de población catalogada como rural, que presenta menores niveles de forma generalizada. El mismo comportamiento se observa en la tasa de pobreza extrema con doble digito para San Vicente.

Llama mucho la atención al que comparar la mayor parte de los indicadores, es posible constatar que San Salvador, se encuentra en situación considerablemente mejor que San Vicente y aun que el promedio de país. 
Dentro de nuestro país tenemos desigualdad en materia de desarrollo territorial, dado que tenemos áreas geográficas como AMSS (Area Metropolitana de San Salvador), que aglutinan tanto actividad económica, como oportunidades para obtener beneficios económicos versus municipios y áreas geográficas con ingresos y niveles de desarrollo considerablemente inferiores.

Gráfico 3. \% Ocupados por Rama de Actividad Económica (San Vicente, San Salvador, El Salvador)

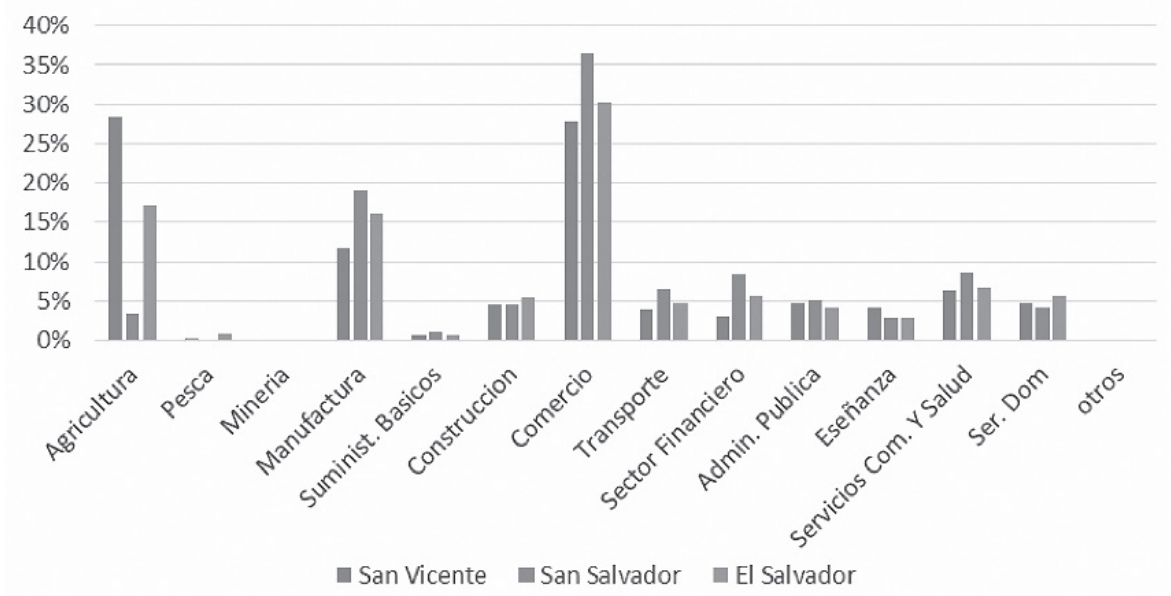

Fuente: Elaboración propia en base a datos de EHPM 2015

Continuado con la misma línea directora para identificar las peculiaridades del departamento de San Vicente, la mayor participación en términos de ocupación lo tiene la agricultura con $28.3 \%$, seguido muy de cerca por el comercio con 27.8\%. Tanto para San Salvador como a nivel país el sector comercio se ubica como el de mayor participación con 36\% y 30\% respectivamente (Ibid).

\subsection{Características de la Investigación de campo}

Para poder llevar a cabo el presente ensayo de investigación se elaboró una encuesta (Anexo 1) en la página e-encuesta disponible en: http: / /www.e-encuesta.com/answer?testld=20YmOt89xps. Para la misma se usaron variables tanto cuantitativas como cualitativas, destinadas a captar las similitudes y peculiaridades de diferentes Micro y pequeña empresas de diferentes rubros, así como los principales obstáculos que afectan la operatividad de las mismas.

El estudio se delimita a empresas con menos de 10 trabajadores ubicadas en la ciudad de San Vicente, para lo que se ubica al "muestreo por selección intencionada o muestreo de conveniencia" como tipo de muestreo a utilizar, teniendo la reducida ventana de tiempo para poder presentar el estudio (Casal y Mateu, 2003). 
Se combinaron medios electrónicos y visitas a microempresas ubicadas en la ciudad de San Vicente, dada la afinidad del investigador con varios de los microempresarios propietarios de negocios. La muestra recopilada en la presente investigación cuenta con 25 participaciones de microempresarios con diferentes tipos negocios y volúmenes de actividad (siguiendo la característica única de menos de 10 trabajadores).

La muestra seleccionada se encuentra ubicada en su mayoría alrededor de las zonas de principal afluencia peatonal y vehicular de la ciudad de San Vicente, tal como se detalla en el mapa:

Figura 1. Mapa de ubicación geográfica de la muestra

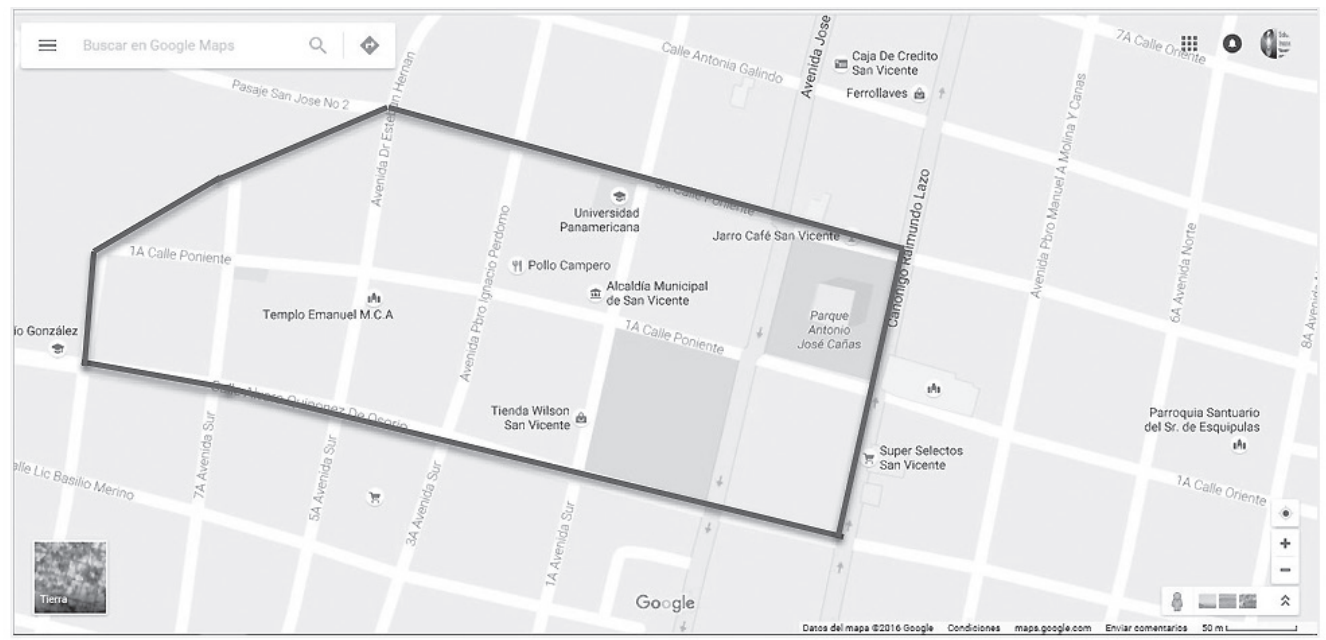

Fuente: Elaboración propia usando Google maps

Para el diseño de la encuesta se tomó como base el estudio realizado por Martínez y Beltrán (2002), donde se llevó a cabo una encuesta de opinión en el entorno del Programa de FUNDAMYPE con el fin de estimar la estimar la gravedad y prioridad de los principales obstáculos que afrontan, así como caracterizar las unidades empresariales entrevistadas. En esencia se persiguen objetivos similares con la presente investigación, aunque la encuesta ha sido acortada en gran parte en las preguntas referentes a información demográfica dada la aversión de participantes por revelar por motivos de seguridad.

Posterior al cierre de la toma de muestra de la encuentra en línea, se procedió a la recopilación de la información en base de dato SPSS para su análisis. Al entrar mayor a detalle sobre la estructura de la encuesta, se cuenta con una serie de preguntas donde se le permite al encuestado seleccionar diferentes opciones como las siguientes: Principal medio para contactar a sus clientes, Principal 
costo de la empresa, principal obstáculo de al que se enfrenta la empresa, Tipos de clientes que atiende la empresa, etc.

Tratando de mantener vinculadas las distintas respuestas en un solo registro por encuestado se usaron variables dicotómicas ( $\mathrm{Si}$, No) para poder obtener la cantidad de respuestas del total de la población que seleccionaron cada una de las opciones múltiples a las preguntas (Ver anexo 2 para un listado completo sobre las variables usadas en SPSS). Adicional en varias de las preguntas se permite al encuestado se le permite seleccionar "Otros" como categoría para brindar una respuesta no disponible entre el abanico de opciones.

\subsection{Hipótesis de investigación}

A través del presente estudio se pretende identificar el potencial de las MYPES para sustentar el crecimiento, así como las siguientes hipótesis de investigación relacionadas a las variables presentes en la investigación de campo:

\section{Hipótesis 1 (Anexo 6.1)}

HO: Existe correlación positiva entre el obstáculo al financiamiento y la cantidad de empleados $(\rho X y \leq 0)$

HA: No existe correlación positiva entre el obstáculo al financiamiento y la cantidad de empleado $(\rho X y>0)$

\section{Hipótesis 2 (Anexo 6.2)}

$\mathrm{HO}$ : Existe correlación positiva redes sociales como medio de contacto a clientes y el acceso a internet en la empresa $(\rho X y \leq 0)$

HA: correlación positiva redes sociales como medio de contacto a clientes y el acceso a internet en la empresa $(\rho X y>0)$

\section{Análisis de los principales resultados y hallazgos}

\subsection{Variables poblacionales}

Para poder hacer un análisis sobre los resultados obtenidos de la encuesta se presentan a continuación una serie de características de los encuestados y sus empresas (Ver anexo 3): 
68 Caracterización de MYPES en el municipio de San Vicente.

Luis Alfredo Chacón Monterrosa

Gráfico 4. Género del propietario de la empresa

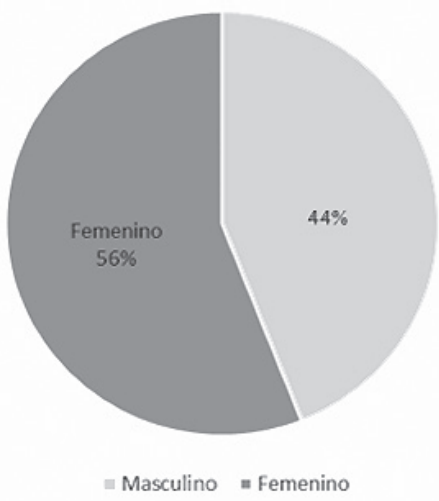

Fuente: Elaboración propia en base a resultados de encuesta

El mayor porcentaje de participación respecto a género de personas encuestadas es femenino con $56 \%$ de participación versus $44 \%$ de participación para género masculino.

Un porcentaje alto de los encuestados han cursado estudios universitarios con $64 \%$, sin embargo como oportunidad detectada posterior a la realización de la encuesta no se incluyó si se hace referencia a haber cursado nivel o si este fue finalizado. Llama la atención de igual forma un $8 \%$ de participación de estudios postgrado. Tales cifras presentan niveles muy por encima de los promedios nacionales.

Gráfico 5. Nivel de Escolaridad de Propietarios o Gerentes de la Empresa

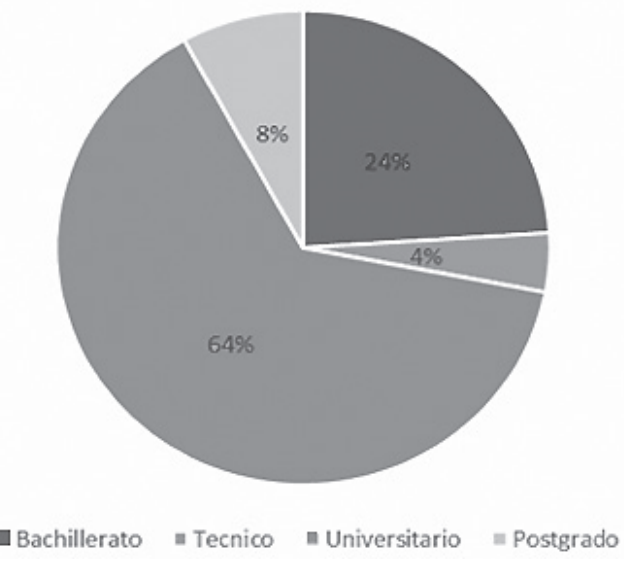

Fuente: Elaboración propia en base a resultados de encuesta 
Entre los diferentes rangos presentados en el grafico a continuación podemos observar que existe una uniformidad en términos de participación con más de $20 \%$ en cada uno. El de mayor participación corresponde a empresas con entre 3-4 empleados. Sin embargo dentro del total de la población de cantidad de trabajadores se identifica un valor atípico por medio de la fórmula: $I C=X \pm 3 \sigma$

$\mathrm{IC}=5.04 \pm 3(4.843)$

$\mathrm{IC}=(-9.489,19.569)$

Con valores de 25 y 12 empleados en dos de las observaciones dentro de la pregunta "cantidad de empleados de la empresa", se realiza la sustitución del mismo por la media para poder eliminar el valor atípico procurando la estabilidad en los estadísticos presentes en la investigación.

Gráfico 6. Cantidad de Empleados en la Empresa

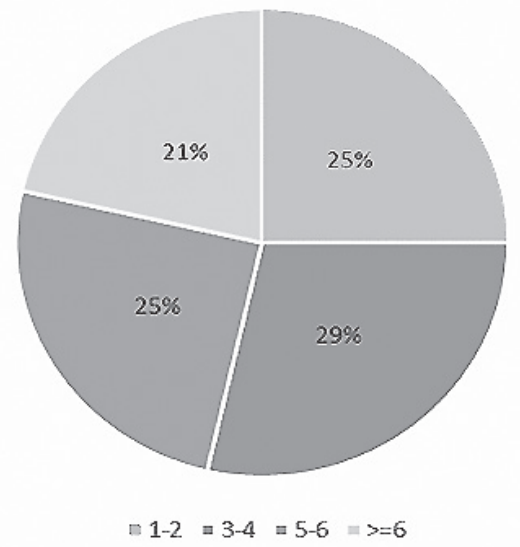

Fuente: Elaboración propia en base a resultados de encuesta

\subsection{Variables de estrategia comercial}

Ya habiendo tratado los aspectos base respecto a la población encuestada, nos adentramos en la serie de variables respecto a la estrategia de penetración al mercado (principal actividad comercial, medios de contacto y tipos de clientes principales) así como el uso de tecnología (en específico el internet).

Las personas encuestadas en con actividades comercial principal en Servicios y comercio presentan la misma participación con $44 \%$ cada una, cuestión que refleja la realidad de la estructura económica de las MYPES dentro del país. 
Gráfico 7. Actividad Comercial de las empresas

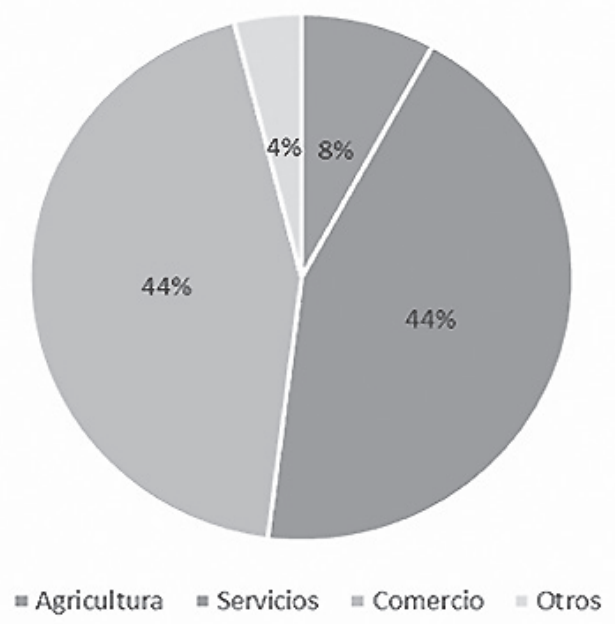

Fuente: Elaboración propia en base a resultados de encuesta

En términos medio más usado por todos los encuestados para conseguir nuevos clientes y mantener los existentes es por medio de visita de los clientes al local comercial de la empresa con $80 \%$ de los encuestados. Seguido por las redes sociales con $56 \%$ de uso volviéndose en el segundo medio más usado para contacto con clientes. Confirmado por un $72 \%$ de los encuestados usando internet para las actividades de sus negocios.

Gráfico 8. Medio de contacto con clientes principales

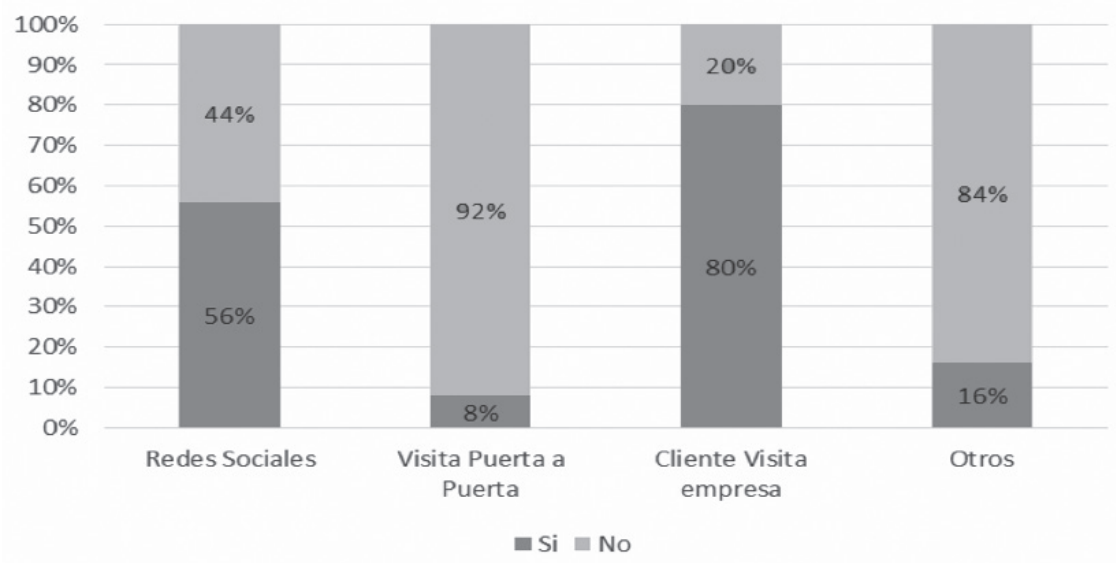

Fuente: Elaboración propia en base a resultados de encuesta

La mayor parte de los microempresarios encuestados identifican al consumidor final como su principal cliente con $92 \%$ de los encuestados sirviendo a esta tipología de cliente y adicional existe cierto encadenamiento productivo con 
empresas de menor tamaño y mayor tamaño con $40 \%$ y $24 \%$ respectivamente de la opinión de los encuestados.

Gráfico 9. Principales Clientes de Microempresarios entrevistados

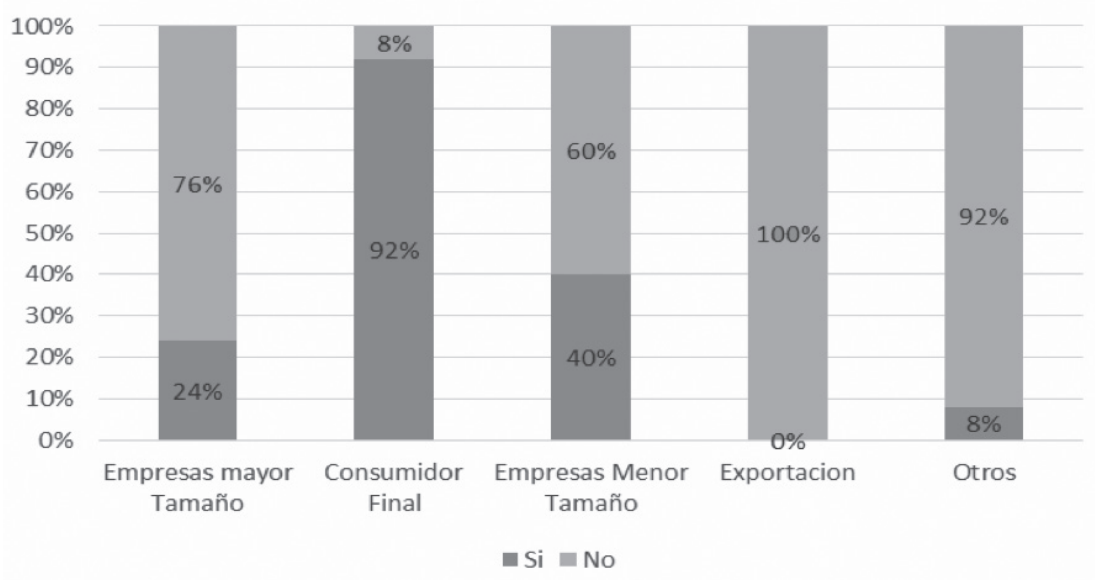

Fuente: Elaboración propia en base a resultados de encuesta

\subsection{Variables de percepción}

Dentro de la parte medular de la investigación y tal como lo expresa Martínez y Beltrán (2002), conocer la percepción de los principales costos y obstáculos que tienen que sobrellevar las MYPES, nos ayudaran a visualizar futuras investigaciones respecto a las medidas que pueden ser impulsadas desde diferentes frentes.

Como es apreciable el $88 \%$ de los microempresarios encuestados ubican a la materia prima como uno de sus principales costos. Con cierto efecto implícito respecto a la amplitud de la respuesta, debido a que encuestados pudieron haber considerado como materia prima productos ya terminados que no sufre transformación y que dentro de su actividad principal se dedican a comercializar o realizar actividades de instalación brinda un servicio.

El siguiente rubro percibido con mayor impacto sobre los costos son los impuestos, que a la vez pueden estar influyendo sobre los costos de la materia prima, debido a todos los gravámenes presentes en la serie de productos usados por los microempresarios para sus procesos productivos. Mayores impuestos encarecen la operatividad de las empresas que muchas veces tienen que sacrificar margen de ganancia, dada la intensa competencia en precios o la elasticidad en la demande que se espera en ciertos bienes de consumo.

De igual forma, la mano de obra es uno de los principales costos para 32\% de los encuestados de los encuestados. El gasto en seguridad también presenta una participación considerable con $24 \%$, siendo la práctica común entre empresas 
privadas ya sea contratar servicios de seguridad privada para custodiar las instalaciones de las empresas, instalar algún sistema de monitoreo remoto (alarmas, cámaras de seguridad) o el pago de la "renta" para garantizar la seguridad de los empresarios y sus empleados a las pandillas.

Gráfico 10. Principales Costos incurridos por Microempresarios entrevistados

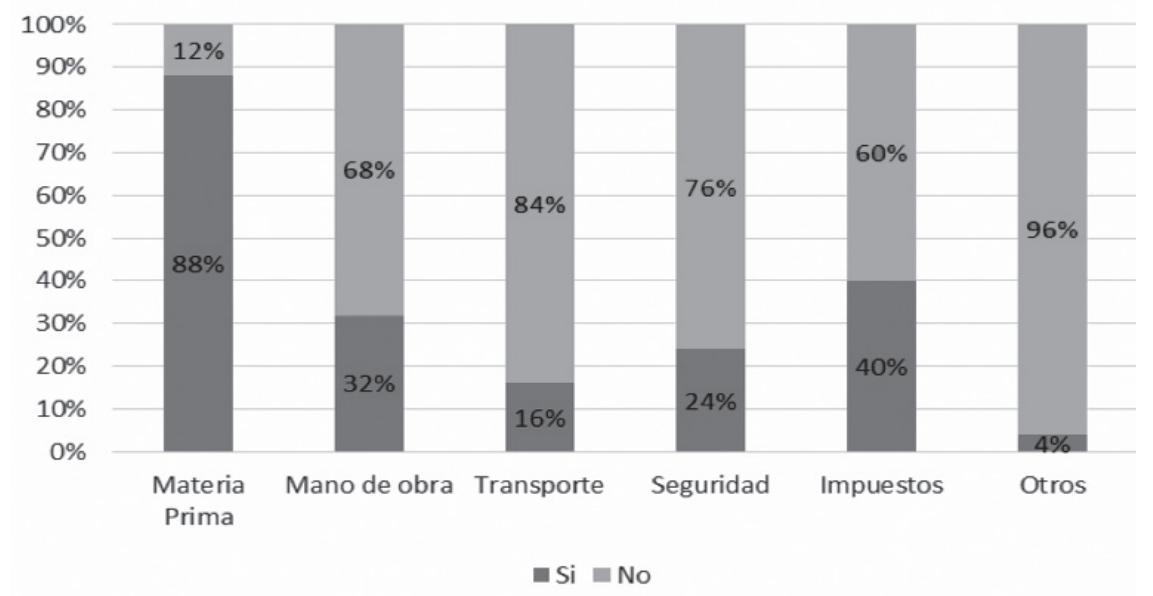

Fuente: Elaboración propia en base a resultados de encuesta

Tal como se expresa en diferentes estudios a nivel internacional (OIT, 2015) y a nivel local (Martínez y Beltrán, 2002) el acceso al financiamiento es siempre uno de los principales obstáculos de los que adolecen las empresa MYPES, dado que en muchas ocasiones carecen de garantías reales para poder volverse clientes de la banca tradicional afectando o retardando el crecimiento de los negocios, debido a no contar con el capital suficiente para invertir, en diferentes rubros que ayuden a mejorar la competitividad de sus empresas o simplemente ayudar a cubrir la operatividad del negocio debido al ciclo de caja con venta al crédito. Muchos de estas empresas usan fuentes de fondeo más costosas como usureros o prestamos en cajas de crédito y bancos cooperativos a tasas de crédito mayores debido a las primas de riesgo con el que es catalogado el segmento.

Aunque existen programas de impulsados desde el gobierno y ONG's para el acceso al financiamiento y asesoría técnica, la cobertura sigue siendo baja, evidenciada en la pequeña participación de encuestados con $16 \%$ y de ese porcentaje únicamente el $4 \%$ manifiesta haber recibido ayuda con impacto positivo en su negocio.

El alto costo de la materia prima es segundo obstáculo con mayor participación con $56 \%$, seguido por el alto costo de los servicios básicos con $48 \%$. De igual 
forma la competencia por clientes con $32 \%$ y el pago de impuestos con $28 \%$ presentan participaciones no despréciales.

Gráfico 11. Principales Obstáculos percibidos por los Microempresarios entrevistados

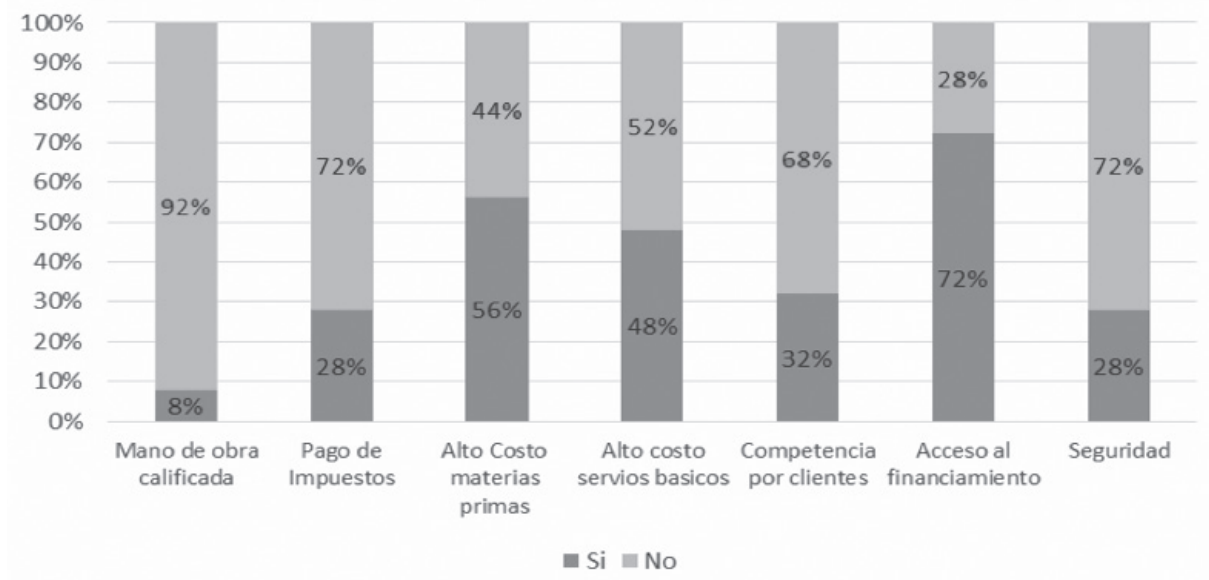

Fuente: Elaboración propia en base a resultados de encuesta

\subsection{Cruces de variables}

Para poder analizar de mejor forma como diferentes variables se entrecruzan y así poder extraer conclusiones sobre los fenómenos que actúan de diferentes formas, respecto a la población sobre la que se está haciendo inferencia estadística. Se presentan una serie de tablas cruzadas creadas usando SPSS, mezclando tanto de características poblacionales como se percepción de los encuestados.

Al usar las variables poblacionales Sexo y grado de escolaridad con principal actividad comercial (Ver anexo 4.1) podemos mencionar que en términos de escolaridad por sexo tanto hombres como mujeres con $63.6 \%$ y $64.3 \%$ de participación reportaron educación a nivel universitario. En cuanto a los hombres $18.2 \%$ de reportaron estudios de postgrado. La principal participación mezclando las 3 variables se encuentra en mujeres con educación universitaria participando en actividades comerciales de servicios con una participación de $20 \%$ sobre el total de encuestados.

Las empresas con consumidores finales como uno de sus principales clientes presentan mayor participación en las actividades empresas especializadas en actividades de comercio que en las de actividades de servicios con $44 \%$ y $36 \%$ respectivamente. Por otro lado las empresas de servicios. La misma situación se presenta en el segmento de consumidores de empresas de mayor tamaño con 
74 Caracterización de MYPES en el municipio de San Vicente.

Luis Alfredo Chacón Monterrosa

mayor participación a favor de empresas en actividades de comercio (ver Anexo 4.2 a 4.5$)$.

El acceso al financiamiento como obstáculo para las empresas se hace más presente en el rango de 5-6 empleados con un 89\% de participación del total en esa categoría, denotando de cierta forma que a partir de cierto nivel de actividad en las empresas las necesidades de financiamiento se hacen más evidentes. Dentro de la población en análisis a mayor - se presenta la hipótesis que será puesta a prueba en el siguiente apartado- nivel de empleados mayor es la necesidad de contar con financiamiento dada la participación creciente de acceso al financiamiento como obstáculo (Ver anexo 4.6).

El alto costo de la materia prima ha demostrado ser tanto uno de los principales costos como un obstáculo para los microempresarios encuestados aunque al observar si existe una diferenciación según cantidad de empleados dentro de la empresa no se observa mayor diferencias significativas ya que aproximadamente representan entre 50-57 por ciento de participación. Sin embargo en la variable costo de servicios básicos se denota una mayor preocupación en las empresas de 5-6 empleados con 55.6\% de participación (Ver Anexo 4.7 a 4.9).

\subsection{Modelos de regresión Múltiple}

Para poder identificar las variables que influencian los resultados y ayudan a predecir la necesidad de financiamiento que perciben los empresarios MYPE se usaron las siguientes variables:

Rango_Empleados (X): Número de empleados por rango ( 1-2, 3-4,5-6,>6)

Sexo (Y): Sexo del propietario (Masculino o Femenino)

Escolaridad (Z): Primaria, Secundaria, Bachillerato, Técnica, Universitaria, Postgrado y Otros

Actividad_Comercial (W): Agricultura, servicios, Comercio, otros

Internet (I): Posee acceso a Internet (Si, No)

Materia_Prima_Costo (R): Es la Materia Prima uno de los costos principales de la empresa (Si,No)

Mano_Obra_Costo (S): Es la Mano de Obra uno de los principales costos de la empresa ( $\mathrm{Si}, \mathrm{No})$

Consumidor_Final_Cliente (T): Es el consumidor final el cliente principal de la empresa (Si, No)

Requisitos_Ley (U): La empresa cumple con los requisitos de Ley (Si, No, parcialmente)

Institucion_Ayuda (V): Solicito ayuda a alguna institución sin fines de lucro o de gobierno (Si,No)

Las diferentes variables seleccionadas para el modelo de regresión múltiple muestran diferentes caras de como la demografía (sexo, escolaridad), actividad económica de la empresa (actividad comercial, Consumidor_Final_Cliente) y 
características respecto a estructura operativa de la empresa ( Materia_Prima_ Costo, Mano_Obra_Costo., Requisitos_Ley), sin el conocimiento respecto a que las mismas agregaran significancia al modelo.

$$
\begin{gathered}
\mathrm{Y}=\text { Acceso al financiamiento (variable dicotómica con valores } 0 \text { y } 1 \text { ) } \\
\mathrm{Y}=2.784+0.047 \mathrm{X}-0.173 \mathrm{Y}-0.40 \mathrm{Z}-0.124 \mathrm{~W}+0.6 \mathrm{I}-0.687 \mathrm{R}-0.248 \mathrm{~S}+0.091 \mathrm{~T}+0.125 \mathrm{U}-0.338 \mathrm{~V}
\end{gathered}
$$

La constante del modelo indica que desde el punto de partida la dificultad de acceso al financiamiento impacta en 2.8 unidades aproximadamente. Existen variables por un lado que impactan la dificultad de acceso al financiamiento de forma positiva como: el número de empleados, el acceso al internet, consumidor final cliente mayoritario de la empresa y cumple los requisitos de ley, por otro lado existe mayor cantidad de variables con signo negativo y magnitudes de diferentes como: sexo, escolaridad, actividad comercial principal, materia prima como uno de los principales costos, mano de obra como uno de los principales costos y solicitud de ayuda a instituciones de gobierno y sin fines de lucro.

Las variables con mayor coeficiente y por consiguiente mayor impacto sobre los resultados del modelo son: el acceso a Internet con coeficiente de 0.6 , nivel de escolaridad de propietario con coeficiente de 0.4 y solicitud de acceso de ayuda a intuiciones de gobierno y sin fines de lucro con coeficiente de 0.338 . En términos globales el modelo obtuvo un coeficiente de correlación de 0.6 lo que indica que el modelo con sus variables explica el $60 \%$ de la variabilidad, por otro lado el coeficiente de correlación ajustado de -0.92 evidencia que hay ciertas variables que no le aportan significancia al modelo (Ver Anexo 5).

\subsection{Resultados de prueba de hipótesis}

- Hipótesis 1: Las pruebas de Chi cuadrado y medidas simétricas en sus diferentes variaciones presentan significancia mayor a 0.05 por lo que se acepta la hipótesis nula

- Hipótesis 2: Las pruebas de Chi cuadrado y medidas simétricas en sus diferentes variaciones presentan significancia cercana a cero por lo que se acepta la hipótesis alternativa.

\section{Conclusiones}

- Definición MYPES: No existe uniformidad en cuanto a la clasificación de las categorías, por lo que de cara a la investigación es necesario la elección de categorías que se ajusten al fenómeno en estudio.

- Hipótesis de investigación: En Relación al planteamiento sobre la capacidad de las MYPES respecto a impulsar el desarrollo sostenido de El Salvador, existe evidencia de sobra que prueba la importancia de las MYPES, dentro de la estructura económica empleando a un alto porcentaje de la población. Por lo que el propiciar condiciones favorables para su desarrollo, podría 
tener economías de escala respecto a todo el aparato productivo en El Salvador.

- Caracterización de las MYPES: Las pequeñas y medianas empresas Salvadoreñas presentan mayor estabilidad y capacidades que propician sus niveles de productividad. En contraste con las microempresas que representan mayores condiciones de vulnerabilidad, bajo nivel de productividad y condiciones laborales desfavorables.

- Limitaciones MYPES: La serie de obstáculos y/o presentados en el presente estudio encabezados por el acceso al financiamiento, deben ser tomados muy en cuenta tanto por los entes desarrolladores de políticas, investigadores sociales y la sociedad civil para poder propiciar el entorno favorable que sirva como caldo de cultivo, para el desarrollo de nuevas empresas y el crecimiento sostenido de las ya existentes.

- Encuesta de opinión: Usando el precedente de Martínez y Beltrán (2002) para el diseño de la encuesta se llegan a conclusiones similares respecto a los principales obstáculos que presenta la población en análisis, siendo el acceso al financiamiento el principal tópico en la mente de los microempresarios encuestados, seguidos por el alto costo de la materia prima y de igual forma el alto costo de los servicios básicos. Adicional se pudo evidenciar que sin embargo existen programas de apoyo a las microempresas es necesario al ampliar la cobertura de los mismos a nivel nacional.

\section{Bibliografía}

Alvarez, M. (2009). Manual de la Micro, Pequeña y Mediana Empresa: Una contribución a la mejora de los sistemas de información y el desarrollo de las políticas públicas. GTZ- DESCA. (pp. 19-24). El Salvador: GTZ.

Consejo Nacional de la Micro y Pequeña Empresa (CONAMYPE). Ley de Fomento, Protección, y Desarrollo de la Micro y Pequeña Empresa. Recuperado de https: / / www.conamype.gob.sv/?page_id=1640

DIGESTYC, (2016). Encuesta de Hogares y Propósitos Múltiples 2015. Dirección General de Estadísticas y Censos (DIGESTYC), Ministerio de Economía.

Organización Internacional del Trabajo (2015). Pequeñas y medianas empresas y creación de empleo decente y productivo. Conferencia Internacional del Trabajo, 104. ${ }^{\text {a }}$ reunión, 2015. (pp. 3 -62). Ginebra, Suiza: OIT.

Tobar Pesantez, L., B. (2014). Las Pequeñas y Medianas Empresas en Cuenca, su Impacto en la Economía Local. (Tesis Doctorado). Universidad de León, España. 


\section{Anexos}

\section{Anexo 1- Estructura de Encuesta}

Objetivo: Esta es una encuesta destinada a captar las similitudes y peculiaridades de diferentes Micro y pequeña empresas de diferentes rubros y ubicaciones geográficas, así como poder identificar los principales obstáculos que afectan la operatividad de las mismas

Instrucciones: No es necesario que coloque ningún tipo de información personal. Debe responder cada las preguntas que se presentan entre selección múltiple y respuesta especifica según se le presenta de acuerdo a las características de su empresa. La información será usa para fines de investigación.

1- Número de empleados de la empresa:

2- Departamento donde se localiza la casa matriz de la empresa:

3- Genero del propietario o representante principal de la empresa
a) Masculino
b) Femenino

4- Podría proporcionar la fecha de fundación de la empresa:

5- Actividad principal de la empresa:
a) Comercio
b) Servicios
c) Agricultura
d) Manufactura de productos
e) Otros: Especifique

6- Grado de escolaridad de directivos o gerentes y propietarios de la empresa:

7- Acceso posee acceso a Internet en la empresa
a) $\mathrm{Si}$
b) No

8- ¿Cuál es el principal medio para contactar a sus clientes?
a) Redes sociales
b) Visitas puerta a puerta

9- Clientes visitan sucursales de la empresa

a) ¿Cuál es el principal costo de la empresa?

b) Materia prima 
c) Mano de obra

d) Transporte

e) Otros: Explique

10- Cuál considera que son sus principales obstáculo para las actividades de la empresa (puede seleccionar más de una respuesta):
a) Acceso al Financiamiento
b) Seguridad
c) Alto costo de los servicios básicos
d) Mano de obra calificada
e) Competencia por clientes
f) Pago de impuestos y otros tributos al gobierno
g) Costos de materias primas y servicios básicos
h) Otros: especifique

11- Quiénes son los principales clientes de la empresa:
a) Otras empresas de gran tamaño
b) Consumidores finales
c) Otras empresas de menor tamaño
d) Exportación
e) Otros: Especifique

12- La empresa se encuentra formalmente establecida (es decir cumple con los requisitos de ley respecto a pago de impuestos, AFP, ISSS, etc.)
a) Sí
b) No

13- ¿Ha solicitado algún tipo de ayuda técnica a alguna institución de gobierno o sin fines de lucro?
a) Si (pase a pregunta 14)
b) No (pase a pregunta 15)

14- ¿Recibió la ayuda que buscaba?
a) No recibí ayuda en absoluto
b) Recibí ayuda aunque no tuvo impacto sobre mi negocio
c) Recibí ayuda y tuvo impacto considerable sobre mi negocio

15- ¿Cómo visualiza a su empresa en futuro ( 2 o más años):
a) Mejores condiciones
b) Iguales condiciones
c) Peores condiciones

16- Si tuviese algún comentario adicional que contribuya al propósito de esta investigación, utilice el siguiente espacio: 


\section{Anexo 2 - Estadísticos de variables oblacionales}

\section{Anexo 2.1}

Departamento donde se localiza la casa matriz de la empresa

\begin{tabular}{lcccc}
\hline Departamento & Frecuencia & Porcentaje & Porcentaje válido & Porcentaje acumulado \\
\hline San Salvador & 8 & 32.0 & 32.0 & 32.0 \\
San Vicente & 15 & 60.0 & 60.0 & 92.0 \\
La Paz & 1 & 4.0 & 4.0 & 96.0 \\
La Libertad & 1 & 4.0 & 4.0 & 100.0 \\
Total & 25 & 100.0 & 100.0 & \\
\hline
\end{tabular}

Fuente: Elaboración propia usando SPSS

Género del propietario o representante principal de la empresa

\begin{tabular}{lcccc}
\hline & Frecuencia & Porcentaje & Porcentaje válido & Porcentaje acumulado \\
\hline Válido & & & & \\
Masculino & 11 & 44.0 & 44.0 & 44 \\
Femenino & 14 & 56.0 & 56.0 & 100.0 \\
Total & 25 & 100.0 & 100.0 & \\
\hline
\end{tabular}

Fuente: Elaboración propia usando SPSS

Grado de escolaridad de directivos, gerentes y/o propietarios de la empresa

\begin{tabular}{lcccc}
\hline Departamento & Frecuencia & Porcentaje & Porcentaje válido & Porcentaje acumulado \\
\hline Válido & & & & \\
Bachillerato & 6 & 24.0 & 24.0 & 24.0 \\
Técnico & 1 & 4.0 & 4.0 & 28.0 \\
Universitario & 16 & 64.0 & 64.0 & 92.0 \\
Postgrado & 2 & 8.0 & 8.0 & 100.0 \\
Total & 25 & 100.0 & 100.0 & \\
\hline
\end{tabular}

Fuente: Elaboración propia usando SPSS

Número de empleados de la empresa (incluyéndose)

\begin{tabular}{lcccc}
\hline & Frecuencia & Porcentaje & Porcentaje válido & Porcentaje acumulado \\
\hline Válido & & & & \\
2 & 7 & 28.0 & 28.0 & 28.0 \\
3 & 5 & 20.0 & 20.0 & 48.0 \\
4 & 3 & 12.0 & 12.0 & 60.0 \\
5 & 4 & 16.0 & 16.0 & 76.0 \\
6 & 3 & 12.0 & 12.0 & 88.0 \\
10 & 1 & 4.0 & 4.0 & 92.0 \\
12 & 1 & 4.0 & 4.0 & 96.0 \\
25 & 1 & 4.0 & 4.0 & 100.0 \\
Total & 25 & 100.0 & 100.0 & \\
\hline
\end{tabular}

Fuente: Elaboración propia usando SPSS 
80 Caracterización de MYPES en el municipio de San Vicente.

Luis Alfredo Chacón Monterrosa

Actividad comercial principal de la empresa (Selecciones una opción)

\begin{tabular}{lcccc}
\hline & Frecuencia & Porcentaje & Porcentaje válido & Porcentaje acumulado \\
\hline Válido & 7 & 28.0 & 28.0 & \\
2 & 5 & 20.0 & 20.0 & 28.0 \\
3 & 3 & 12.0 & 12.0 & 48.0 \\
4 & 4 & 16.0 & 16.0 & 60.0 \\
5 & 3 & 12.0 & 12.0 & 76.0 \\
6 & 1 & 4.0 & 4.0 & 88.0 \\
10 & 1 & 4.0 & 4.0 & 92.0 \\
12 & 1 & 4.0 & 4.0 & 96.0 \\
25 & 25 & 100.0 & 100.0 & 100.0 \\
Total & & & & \\
\hline
\end{tabular}

Fuente: Elaboración propia usando SPSS

\section{Estadísticos}

\begin{tabular}{lccccc}
\hline & $\begin{array}{l}\text { Departamento } \\
\text { donde se } \\
\text { localiza la } \\
\text { casa matriz } \\
\text { de la empresa }\end{array}$ & $\begin{array}{l}\text { Género del } \\
\text { propietario o } \\
\text { representatnte } \\
\text { principal de la } \\
\text { empresa }\end{array}$ & $\begin{array}{l}\text { Grado de es- } \\
\text { colaridad de } \\
\text { directivos, } \\
\text { gerentes y/o } \\
\text { propietarios } \\
\text { de la empresa }\end{array}$ & $\begin{array}{l}\text { Número de } \\
\text { empleados de } \\
\text { la empresa } \\
\text { (incluyéndose) }\end{array}$ & $\begin{array}{l}\text { Actividad com- } \\
\text { ercial principal } \\
\text { de la empresa } \\
\text { (seleccione una } \\
\text { opción) }\end{array}$ \\
\hline N Válido & 25 & 25 & 25 & 25 & 25 \\
Perdidos & 0 & 0 & 0 & 0 & 0 \\
Media & 3.5200 & 1.5600 & 4.5600 & 5.04 & 2.4400 \\
Mediana & 4.000 & 2.0000 & 5.0000 & 4.00 & 2.0000 \\
Moda & 4.00 .2 .46847 & 2.00 & 5.00 & 2 & $2.00 a$ \\
$\begin{array}{l}\text { Desviación } \\
\text { estándar }\end{array}$ & 2.46847 & .50662 & .96090 & 4.843 & .71181 \\
Varianza & 6.093 & .257 & .923 & 23.457 & .507 \\
\hline
\end{tabular}

Fuente: Elaboración propia usando SPSS 


\section{Anexo 3 - Tablas cruzadas}

\section{Anexo 3.1}

Grado de escolaridad de directivos, gerentes y/o propietarios de la empresa:'Actividad comercial principal de la empresa ( Seleccione una opción): "Genero del propietario o representante principal de la empresa tabulación cruzada

\begin{tabular}{|c|c|c|c|c|c|c|c|c|}
\hline & & & & \multicolumn{4}{|c|}{$\begin{array}{l}\text { Actividad comercial principal de la empresa ( Seleccione una } \\
\text { opción): }\end{array}$} & \multirow[b]{2}{*}{ Total } \\
\hline \multicolumn{4}{|c|}{ Genero del propietario o representante principal de la empresa } & Agricultura & Servicios & Comercio & Otros & \\
\hline \multirow[t]{8}{*}{ Masculino } & \multirow{6}{*}{$\begin{array}{l}\text { Grado de escolaridad de } \\
\text { directivos, gerentes y/o } \\
\text { propietarios de la } \\
\text { empresa: }\end{array}$} & Bachillerato & Recuento & 0 & 0 & 2 & & 2 \\
\hline & & & $\%$ del total & $0.0 \%$ & $0.0 \%$ & $18.2 \%$ & & $18.2 \%$ \\
\hline & & Universitario & Recuento & 1 & 3 & 3 & & 7 \\
\hline & & & $\%$ del total & $9.1 \%$ & $27.3 \%$ & $27.3 \%$ & & $63.6 \%$ \\
\hline & & Postgrado & Recuento & 0 & 2 & 0 & & 2 \\
\hline & & & $\%$ del total & $0.0 \%$ & $18.2 \%$ & $0.0 \%$ & & $18.2 \%$ \\
\hline & \multirow[t]{2}{*}{ Total } & & Recuento & 1 & 5 & 5 & & 11 \\
\hline & & & $\%$ del total & $9.1 \%$ & $45.5 \%$ & $45.5 \%$ & & $100.0 \%$ \\
\hline \multirow[t]{8}{*}{ Femenino } & \multirow{6}{*}{$\begin{array}{l}\text { Grado de escolaridad de } \\
\text { directivos, gerentes y/o } \\
\text { propietarios de la } \\
\text { empresa: }\end{array}$} & Bachillerato & Recuento & 0 & 1 & 2 & 1 & 4 \\
\hline & & & $\%$ del total & $0.0 \%$ & $7.1 \%$ & $14.3 \%$ & $7.1 \%$ & $28.6 \%$ \\
\hline & & Tecnico & Recuento & 0 & 0 & 1 & 0 & 1 \\
\hline & & & $\%$ del total & $0.0 \%$ & $0.0 \%$ & $7.1 \%$ & $0.0 \%$ & $7.1 \%$ \\
\hline & & Universitario & Recuento & 1 & 5 & 3 & 0 & 9 \\
\hline & & & $\%$ del total & $7.1 \%$ & $35.7 \%$ & $21.4 \%$ & $0.0 \%$ & $64.3 \%$ \\
\hline & \multirow[t]{2}{*}{ Total } & & Recuento & 1 & 6 & 6 & 1 & 14 \\
\hline & & & $\%$ del total & $7.1 \%$ & $42.9 \%$ & $42.9 \%$ & $7.1 \%$ & $100.0 \%$ \\
\hline \multirow[t]{10}{*}{ Total } & \multirow{8}{*}{$\begin{array}{l}\text { Grado de escolaridad de } \\
\text { directivos, gerentes y/o } \\
\text { propietarios de la } \\
\text { empresa: }\end{array}$} & Bachillerato & Recuento & 0 & 1 & 4 & 1 & 6 \\
\hline & & & $\%$ del total & $0.0 \%$ & $4.0 \%$ & $16.0 \%$ & $4.0 \%$ & $24.0 \%$ \\
\hline & & Tecnico & Recuento & 0 & 0 & 1 & 0 & 1 \\
\hline & & & $\%$ del total & $0.0 \%$ & $0.0 \%$ & $4.0 \%$ & $0.0 \%$ & $4.0 \%$ \\
\hline & & Universitario & Recuento & 2 & 8 & 6 & 0 & 16 \\
\hline & & & $\%$ del total & $8.0 \%$ & $32.0 \%$ & $24.0 \%$ & $0.0 \%$ & $64.0 \%$ \\
\hline & & Postgrado & Recuento & 0 & 2 & 0 & 0 & 2 \\
\hline & & & $\%$ del total & $0.0 \%$ & $8.0 \%$ & $0.0 \%$ & $0.0 \%$ & $8.0 \%$ \\
\hline & \multirow[t]{2}{*}{ Total } & & Recuento & 2 & 11 & 11 & 1 & 25 \\
\hline & & & $\%$ del total & $8.0 \%$ & $44.0 \%$ & $44.0 \%$ & $4.0 \%$ & $100.0 \%$ \\
\hline
\end{tabular}

Fuente: Elaboración propia usando SPSS

\section{Anexo 3.2}

Consumidor_Final_Cliente`Actividad comercial principal de la empresa ( Seleccione una opción): tabulación cruzada

\begin{tabular}{|c|c|c|c|c|c|c|c|}
\hline & & & \multicolumn{4}{|c|}{$\begin{array}{l}\text { Actividad comercial principal de la empresa ( Seleccione una } \\
\qquad \text { opción): }\end{array}$} & \multirow[b]{2}{*}{ Total } \\
\hline & & & Agricultura & Servicios & Comercio & Otros & \\
\hline \multirow{4}{*}{$\begin{array}{l}\text { Consumidor_Final_Clien } \\
\text { te }\end{array}$} & $\mathrm{Si}$ & Recuento & 2 & 9 & 11 & 1 & 23 \\
\hline & & $\%$ del total & $8.0 \%$ & $36.0 \%$ & $44.0 \%$ & $4.0 \%$ & $92.0 \%$ \\
\hline & No & Recuento & 0 & 2 & 0 & 0 & 2 \\
\hline & & $\%$ del total & $0.0 \%$ & $8.0 \%$ & $0.0 \%$ & $0.0 \%$ & $8.0 \%$ \\
\hline \multirow[t]{2}{*}{ Total } & & Recuento & 2 & 11 & 11 & 1 & 25 \\
\hline & & $\%$ del total & $8.0 \%$ & $44.0 \%$ & $44.0 \%$ & $4.0 \%$ & $100.0 \%$ \\
\hline
\end{tabular}

Fuente: Elaboración propia usando SPSS 
82 Caracterización de MYPES en el municipio de San Vicente.

Luis Alfredo Chacón Monterrosa

\section{Anexo 3.3}

Otras_Empr_Mayor_Cliente ^Actividad comercial principal de la empresa ( Seleccione una opción): tabulación cruzada

\begin{tabular}{|c|c|c|c|c|c|c|c|}
\hline & & & \multicolumn{4}{|c|}{$\begin{array}{l}\text { Actividad comercial principal de la empresa ( Seleccione una } \\
\qquad \text { opción): }\end{array}$} & \multirow[b]{2}{*}{ Total } \\
\hline & & & Agricultura & Servicios & Comercio & Otros & \\
\hline \multirow{4}{*}{$\begin{array}{l}\text { Otras_Empr_Mayor_Clie } \\
\text { nte }\end{array}$} & \multirow[t]{2}{*}{ Si } & Recuento & 0 & 2 & 4 & 0 & 6 \\
\hline & & $\%$ del total & $0.0 \%$ & $8.0 \%$ & $16.0 \%$ & $0.0 \%$ & $24.0 \%$ \\
\hline & \multirow[t]{2}{*}{ No } & Recuento & 2 & 9 & 7 & 1 & 19 \\
\hline & & $\%$ del total & $8.0 \%$ & $36.0 \%$ & $28.0 \%$ & $4.0 \%$ & $76.0 \%$ \\
\hline \multirow{2}{*}{\multicolumn{2}{|c|}{ Total }} & Recuento & 2 & 11 & 11 & 1 & 25 \\
\hline & & $\%$ del total & $8.0 \%$ & $44.0 \%$ & $44.0 \%$ & $4.0 \%$ & $100.0 \%$ \\
\hline
\end{tabular}

Fuente: Elaboración propia usando SPSS

\section{Anexo 3.4}

Otras_Empr_Menor_Cliente`Actividad comercial principal de la empresa ( Seleccione una opción): tabulación cruzada

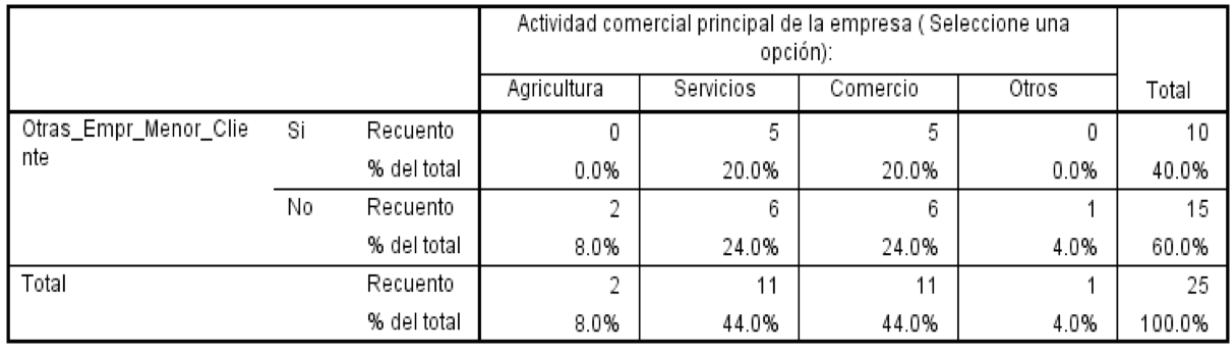

Fuente: Elaboración propia usando SPSS

Anexo 3.5

Mano_Obra_Cal_ObsRango_Empleados tabulación cruzada

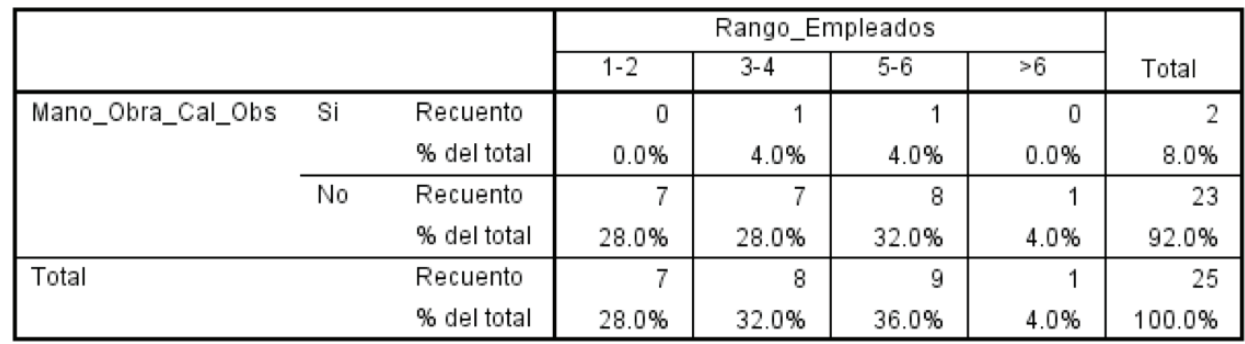

Fuente: Elaboración propia usando SPSS 
Anexo 3.6

Acceso_Financiamiento_Obs ${ }^{\star}$ Rango_Empleados tabulación cruzada

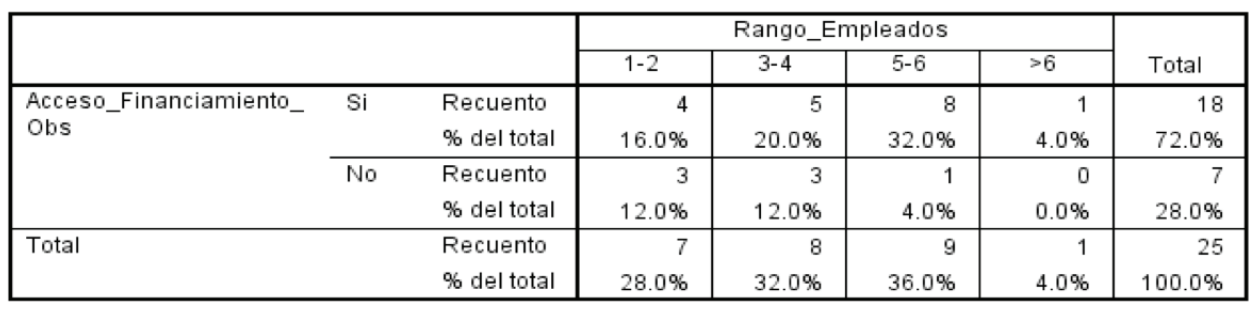

Fuente: Elaboración propia usando SPSS

\section{Anexo 3.7}

Alto_Cost_Ser_Obs ^Rango_Empleados tabulación cruzada

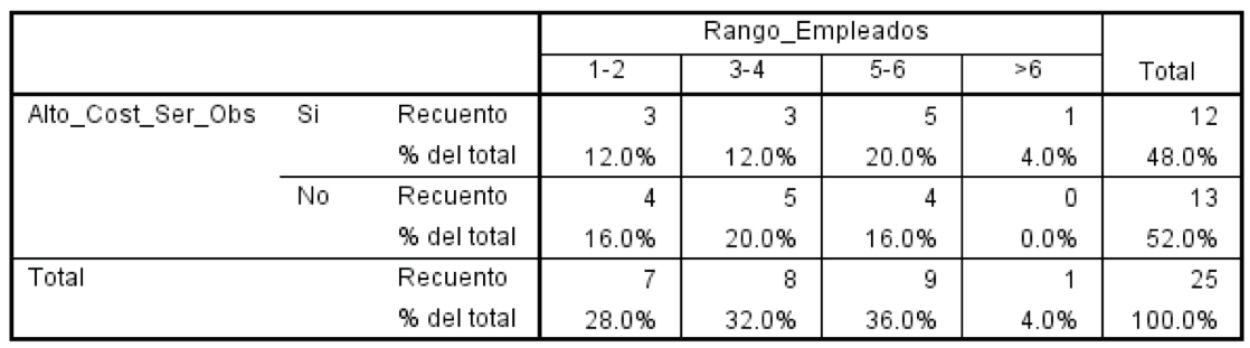

Fuente: Elaboración propia usando SPSS

\section{Anexo 3.8}

Alto_Costo_Mat_Obs ^Rango_Empleados tabulación cruzada

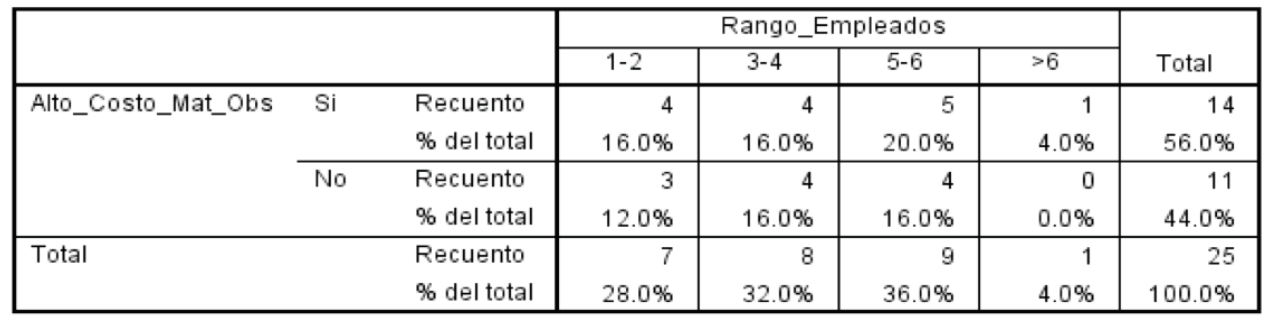

Fuente: Elaboración propia usando SPSS 
84 Caracterización de MYPES en el municipio de San Vicente.

Luis Alfredo Chacón Monterrosa

\section{Anexo 3.9}

Pago_Imp_ObsRango_Empleados tabulación cruzada

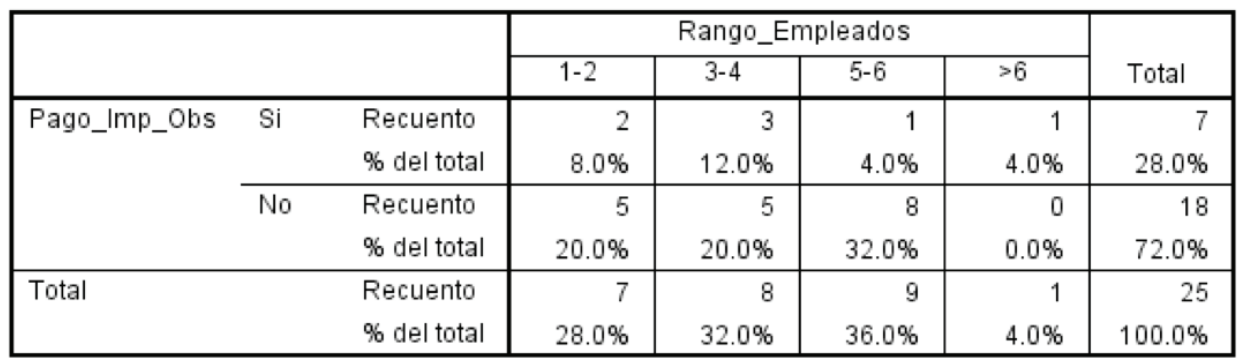

Fuente: Elaboración propia usando SPSS

\section{Anexo 4 - Regresión Múltiple}

Estadísticos descriptivos

\begin{tabular}{|c|c|c|c|}
\hline & Media & $\begin{array}{c}\text { Desviación } \\
\text { estándar }\end{array}$ & $\mathrm{N}$ \\
\hline $\begin{array}{l}\text { Acceso_Financiamiento_Ob } \\
\text { s } \\
\text { Rango_Empleados } \\
\text { Genero del propietario o } \\
\text { representante principal de la } \\
\text { empresa } \\
\text { Grado de escolaridad de } \\
\text { directivos, gerentes y/o } \\
\text { propietarios de la empresa: } \\
\text { Actividad comercial principal } \\
\text { de la empresa ( Seleccione } \\
\text { una opción): } \\
\text { Posee acceso a Internet en } \\
\text { su empresa: } \\
\text { Materia_Prima_Costo } \\
\text { Mano_Obra_Costo } \\
\text { Consumidor_Final_Cliente } \\
\text { ¿La empresa se encuentra } \\
\text { formalmente establecida (es } \\
\text { decir cumple con los } \\
\text { requisitos de ley respecto a } \\
\text { pago de impuestos, AFP, } \\
\text { ISSS, etc.)? } \\
\text { ¿Ha solicitado algún tipo de } \\
\text { ayuda técnica a alguna } \\
\text { institución de gobierno o sin } \\
\text { fines de lucro? }\end{array}$ & $\begin{array}{r}2.4400 \\
.7200 \\
1.1200 \\
1.6800 \\
1.0800\end{array}$ & $\begin{array}{l}.96090 \\
.71181 \\
.45826 \\
.33166 \\
.47610 \\
.27689\end{array}$ & $\begin{array}{l}25 \\
25 \\
25 \\
25\end{array}$ \\
\hline
\end{tabular}

Fuente: Elaboración propia usando SPSS 
Resumen del modelo

\begin{tabular}{|l|l|r|r|r|}
\hline Modelo & $\mathrm{R}$ & R cuadrado & $\begin{array}{c}\text { Error } \\
\text { R cuadrado } \\
\text { ajustado }\end{array}$ & $\begin{array}{c}\text { Estándar de } \\
\text { la estimación }\end{array}$ \\
\hline 1 & $.602^{\mathrm{a}}$ & .363 & -.092 & .47897 \\
\hline
\end{tabular}

a. Predictores: (Constante), ¿Ha solicitado algún tipo de ayuda técnica a alguna institución de gobierno o sin fines de lucro?, Posee acceso a Internet en su empresa:, Materia_Prima_Costo, Actividad comercial principal de la empresa (Seleccione una opción):, Genero del propietario o representante principal de la empresa, ¿La empresa se encuentra formalmente establecida (es decir cumple con los requisitos de ley respecto a pago de impuestos, AFP, ISSS, etc.)?, Consumidor_Final_Cliente, Rango_Empleados, Mano_Obra_Costo, Grado de escolaridad de directivos, gerentes y/o propietarios de la empresa:

Fuente: Elaboración propia usando SPSS

\section{ANOVA}

\begin{tabular}{|ll|r|r|r|r|r|}
\hline \multicolumn{2}{|l|}{ Modelo } & \multicolumn{1}{c|}{$\begin{array}{c}\text { Suma de } \\
\text { cuadrados }\end{array}$} & \multicolumn{1}{c|}{ gl } & $\begin{array}{c}\text { Media } \\
\text { cuadrática }\end{array}$ & \multicolumn{1}{c|}{$\mathrm{F}$} & Sig. \\
\hline 1 & Regresión & 1.828 & 10 & .183 & .797 & $.635^{\mathrm{b}}$ \\
& Residuo & 3.212 & 14 & .229 & & \\
& Total & 5.040 & 24 & & & \\
\hline
\end{tabular}

a. Variable dependiente: Acceso_Financiamiento_Obs

b. Predictores: (Constante), ¿Ha solicitado algún tipo de ayuda técnica a alguna institución de gobierno o sin fines de lucro?, Posee acceso a Internet en su empresa:, Materia_Prima_Costo, Actividad comercial principal de la empresa (Seleccione una opción):, Genero del propietario o representante principal de la empresa, ¿La empresa se encuentra formalmente establecida (es decir cumple con los requisitos de ley respecto a pago de impuestos, AFP, ISSS, etc.)?, Consumidor_Final_Cliente, Rango_Empleados, Mano_Obra_Costo, Grado de escolaridad de directivos, gerentes y/o propietarios de la empresa:

Fuente: Elaboración propia usando SPSS 
86 Caracterización de MYPES en el municipio de San Vicente.

Luis Alfredo Chacón Monterrosa

Coeficientes $^{\mathrm{a}}$

\begin{tabular}{|c|c|c|c|c|c|c|c|c|c|}
\hline \multirow{2}{*}{\multicolumn{2}{|c|}{ Modelo }} & \multicolumn{2}{|c|}{$\begin{array}{l}\text { Coeficientes no } \\
\text { estandarizados }\end{array}$} & \multirow{2}{*}{$\begin{array}{c}\text { Coeficientes } \\
\text { estandarizad } \\
\text { os }\end{array}$} & \multirow[b]{2}{*}{$t$} & \multirow[b]{2}{*}{ Sig. } & \multicolumn{3}{|c|}{ Correlaciones } \\
\hline & & B & $\begin{array}{l}\text { Error } \\
\text { estándar }\end{array}$ & & & & Orden cero & Parcial & Parte \\
\hline \multirow[t]{8}{*}{1} & (Constante) & 2.784 & 1.654 & & 1.683 & .115 & & & \\
\hline & Rango_Empleados & .047 & .081 & .147 & .578 & .573 & .328 & .153 & .123 \\
\hline & $\begin{array}{l}\text { Grado de escolaridad de } \\
\text { directivos, gerentes y/o } \\
\text { propietarios de la } \\
\text { empresa: }\end{array}$ & -.040 & .158 & -.083 & -.252 & .805 & .087 & -.067 & -.054 \\
\hline & $\begin{array}{l}\text { Posee acceso a Internet } \\
\text { en su empresa: }\end{array}$ & .060 & .248 & .060 & .241 & .813 & .206 & .064 & .051 \\
\hline & Materia_Prima_Costo & -.687 & .397 & -.498 & -1.730 & .106 & -.318 & -.420 & -.369 \\
\hline & Mano_Obra_Costo & -.248 & .277 & -.258 & -.895 & .386 & -.237 & -.233 & -.191 \\
\hline & $\begin{array}{l}\text { Consumidor_Final_Clien } \\
\text { te }\end{array}$ & .091 & .445 & .055 & .205 & .841 & .184 & .055 & .044 \\
\hline & $\begin{array}{l}\text { ¿La empresa se } \\
\text { encuentra formalmente } \\
\text { establecida (es decir } \\
\text { cumple con los } \\
\text { requisitos de ley respecto } \\
\text { a pago de impuestos, } \\
\text { AFP, ISSS, etc.)? }\end{array}$ & .125 & .163 & .213 & .765 & .457 & .135 & .200 & .163 \\
\hline
\end{tabular}

Fuente: Elaboración propia usando SPSS

\section{Anexo 5 - Prueba de hipótesis}

\section{Anexo 5.1}

Pruebas de chi-cuadrado

\begin{tabular}{|l|r|r|r|}
\hline & Valor & gl & $\begin{array}{c}\text { Sig. asintótica } \\
\text { (2 caras) }\end{array}$ \\
\hline $\begin{array}{l}\text { Chi-cuadrado de } \\
\text { Pearson }\end{array}$ & $2.787^{\mathrm{a}}$ & 3 & .426 \\
$\begin{array}{l}\text { Razón de verosimilitud } \\
\text { Asociación lineal por } \\
\text { lineal }\end{array}$ & 3.223 & 3 & .359 \\
$\mathrm{~N}$ de casos válidos & 2.575 & 1 & .109 \\
\hline
\end{tabular}

a. 5 casillas $(62.5 \%)$ han esperado un recuento menor que 5 . El recuento minimo esperado es .28 . 
Pruebas de chi-cuadrado

\begin{tabular}{|l|r|r|r|}
\hline & \multicolumn{1}{|c|}{ Valor } & gl & \multicolumn{1}{|c|}{$\begin{array}{c}\text { Sig. asintótica } \\
\text { (2 caras) }\end{array}$} \\
\hline Chi-cuadrado de & $2.787^{\mathrm{a}}$ & 3 & .426 \\
Pearson & 3.223 & 3 & .359 \\
Razón de verosimilitud & 2.575 & 1 & .109 \\
Asociación lineal por & 25 & & \\
lineal & $\mathrm{N}$ de casos válidos & & \\
\hline
\end{tabular}

a. 5 casillas $(62.5 \%)$ han esperado un recuento menor que 5 . El recuento mínimo esperado es 28 .

Medidas direccionales

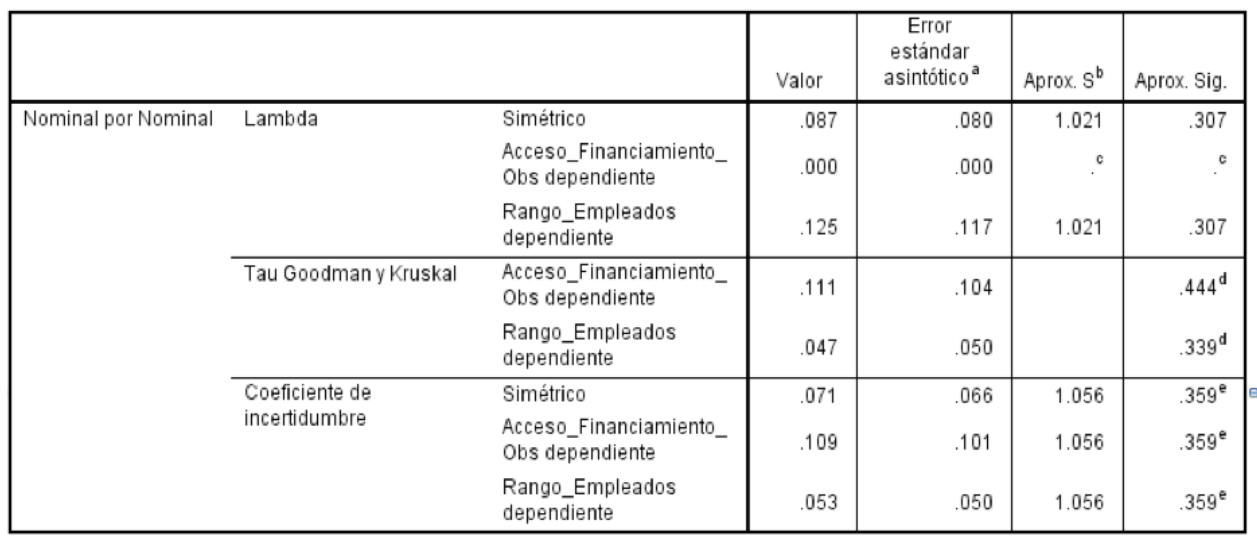

a. No se supone la hipótesis nula.

b. Utilización del error estándar asintótico que asume la hipótesis nula.

c. No se puede calcular porque el error estándar asintótico es igual a cero.

d. Se basa en la aproximación de chi-cuadrado

e. Probabilidad de chi-cuadrado de razón de verosimilitud.

Medidas simétricas

\begin{tabular}{|c|c|c|c|c|c|}
\hline & & Valor & $\begin{array}{c}\text { Error } \\
\text { estándar } \\
\text { asintótico }^{a}\end{array}$ & Aprox. $S^{b}$ & Aprox. Sig. \\
\hline Nominal por Nominal & $\begin{array}{l}\text { Phi } \\
\text { V de Cramer } \\
\text { Coeficiente de } \\
\text { contingencia }\end{array}$ & $\begin{array}{l}.334 \\
.334 \\
.317\end{array}$ & & & $\begin{array}{l}.426 \\
.426 \\
.426\end{array}$ \\
\hline
\end{tabular}
a. No se supone la hipótesis nula.
b. Utilización del error estándar asintótico que asume la hipótesis nula.
c. Se basa en aproximación normal.

Fuente: Elaboración propia usando SPSS 
88 Caracterización de MYPES en el municipio de San Vicente.

Luis Alfredo Chacón Monterrosa

\section{Anexo 5.2}

Pruebas de chi-cuadrado

\begin{tabular}{|c|c|c|c|c|c|}
\hline & Valor & gl & $\begin{array}{l}\text { Sig. asintótica } \\
\text { ( } 2 \text { caras) }\end{array}$ & $\begin{array}{c}\text { Significación } \\
\text { exacta ( } 2 \\
\text { caras) }\end{array}$ & $\begin{array}{c}\text { Significación } \\
\text { exacta (1 } \\
\text { cara) }\end{array}$ \\
\hline $\begin{array}{l}\text { Chi-cuadrado de } \\
\text { Pearson }\end{array}$ & $12.374^{a}$ & 1 & .000 & & \\
\hline $\begin{array}{l}\text { Corrección de } \\
\text { continuidad }\end{array}$ & 9.418 & 1 & .002 & & \\
\hline Razón de verosimilitud & 15.227 & 1 & .000 & & \\
\hline Prueba exacta de Fisher & & & & .001 & .001 \\
\hline $\begin{array}{l}\text { Asociación lineal por } \\
\text { lineal }\end{array}$ & 11.879 & 1 & .001 & & \\
\hline $\mathrm{N}$ de casos válidos & 25 & & & & \\
\hline
\end{tabular}

a. 2 casillas (50.0\%) han esperado un recuento menor que 5. El recuento mínimo esperado es 3.08 .

b. Sólo se ha calculado para una tabla $2 \times 2$

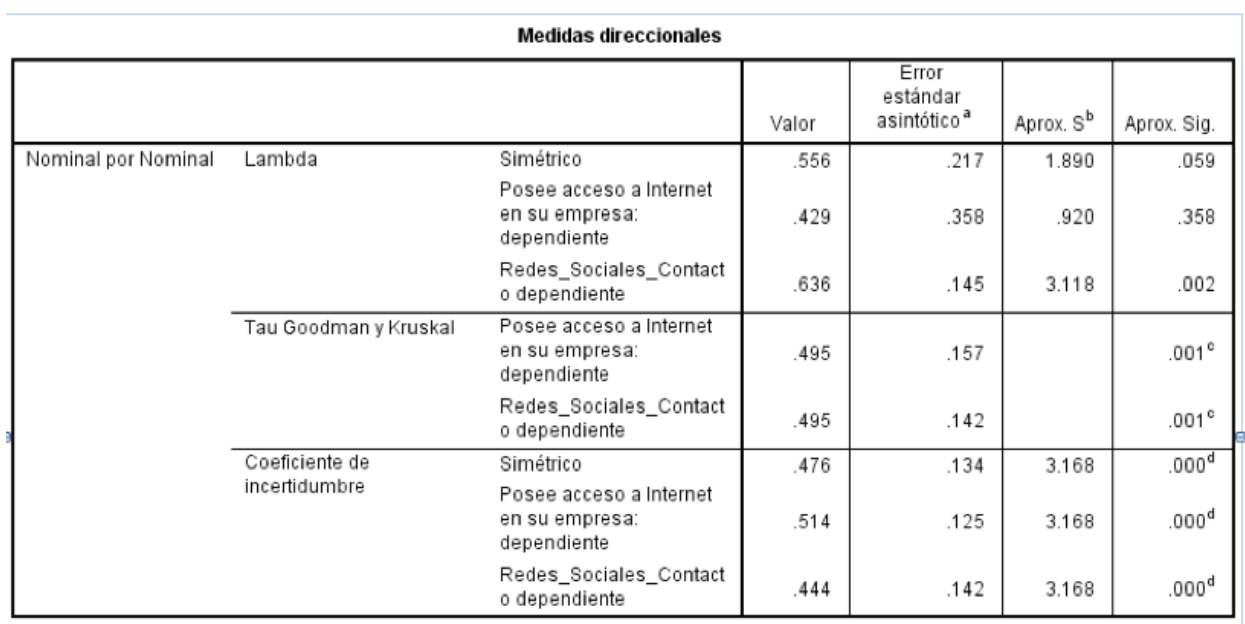

a. No se supone la hipótesis nula.

b. Utilización del error estándar asintótico que asume la hipótesis nula

c. Se basa en la aproximación de chi-cuadrado

d. Probabilidad de chi-cuadrado de razón de verosimilitud

Medidas simétricas

\begin{tabular}{|c|c|c|c|c|c|}
\hline & & Valor & $\begin{array}{c}\text { Error } \\
\text { estándar } \\
\text { asintótico }^{a}\end{array}$ & Aprox. $\mathrm{S}^{\mathrm{b}}$ & Aprox. Sig. \\
\hline Nominal por Nominal & $\begin{array}{l}\text { Phi } \\
V \text { de Cramer } \\
\text { Coeficiente de } \\
\text { contingencia }\end{array}$ & $\begin{array}{l}.704 \\
.704 \\
.575\end{array}$ & & & $\begin{array}{l}.000 \\
.000 \\
.000\end{array}$ \\
\hline Intervalo por intervalo & $\mathrm{R}$ de persona & .704 & .116 & 4.748 & $.000^{c}$ \\
\hline $\begin{array}{l}\text { Ordinal por ordinal } \\
\mathrm{N} \text { de casos válidos }\end{array}$ & $\begin{array}{l}\text { Correlación de } \\
\text { Spearman }\end{array}$ & $\begin{array}{r}.704 \\
25\end{array}$ & .116 & 4.748 & $.000^{\mathrm{c}}$ \\
\hline
\end{tabular}

a. No se supone la hipótesis nula.

b. Utilización del error estándar asintótico que asume la hipótesis nula.

c. Se basa en aproximación normal.

Fuente: Elaboración propia usando SPSS 